Evaluation of No-Clean Solder Process

Designed to Eliminate the Use of

Ozone-Depleting Chemicals

M. T. Paffett

J.D. Farr

Y.C. Rogers

W. B. Hutchinson

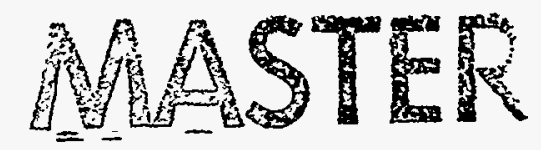




\section{DISCLAIMER}

This report was prepared as an account of work sponsored by an agency of the United States Government. Neither the United States Government nor any agency thereof, nor any of their employees, make any warranty, express or implied, or assumes any legal liability or responsibility for the accuracy, completeness, or usefulness of any information, apparatus, product, or process disclosed, or represents that its use would not infringe privately owned rights. Reference herein to any specific commercial product, process, or service by trade name, trademark, manufacturer, or otherwise does not necessarily constitute or imply its endorsement, recommendation, or favoring by the United States Government or any agency thereof. The views and opinions of authors expressed herein do not necessarily state or reflect those of the United States Government or any agency thereof. 


\section{DISCLAIMER}

Portions of this document may be illegible in electronic image products. Images are produced from the best available original document. 


\title{
EVALUATION OF NO-CLEAN SOLDER PROCESS DESIGNED TO ELIMINATE THE USE OF OZONE-DEPLETING CHEMICALS
}

\author{
by
}

M. T. Paffett, J. D. Farr, Y. C. Rogers, and W. B. Hutchinson

\begin{abstract}
This paper summarizes the LANL contributions to a joint Motorola/SNLA/LANL cooperative research and development agreement study on the reliability of an alternative solder process that is intended to reduce or eliminate the use of ozone-depleting chemicals in the manufacture of printed wire boards (PWBs). This process is termed self-cleaning because of the nature of the thermal chemistry associated with the adipic and formic acid components used in place of traditional solder rosin fluxes. Traditional rosin fluxes used in military electronic hardware applications are cleaned (by requirement) using chlorofluorohydrocarbons. The LANL contribution centers around analytical determination of PWB cleanliness after soldering using the self-cleaning method. Results of these analytical determinations involving primarily surface analysis of boards following temperature, temperature and humidity, and long-term storage testing are described with representative data. It is concluded that the self-cleaning process leaves behind levels of solid residue that are visually and analytically observable using most of these surface analysis techniques. The materials compatibility of electronic components soldered using the self-cleaning soldering process is more fully described in the project report issued by SNLA that encompasses the complete project with statistical lifetime and accelerated aging studies. Analytical surface specificity and suggestions for further work are also given.
\end{abstract}




\title{
INTRODUCTION
}

\begin{abstract}
Alleviating the environmental destruction of the earth's protective ozone layer is one of today's largest pressing scientific and societal concerns. Solvent emissions that result from cleaning electronic parts such as printed wiring boards (PWB) are primary contributors to this destruction. Environmental legislation and international cooperative efforts, such as the Montreal Protocol, are striving to eliminate all ozone depleting chemical (ODC) usage by 2000 . The electronics manufacturing industry has responded to this challenge by developing new self-cleaning soldering processes and by using alternative cleaning agents, which eliminate the need for subsequent PWB cleaning using chlorofluorohydrocarbons. However, military hardware applications demand unusually stringent cleanliness and reliability of manufactured electronic components. The new processes and alternative soldering processes and cleaning methods have not been approved for military application.
\end{abstract}

The program is a joint effort undertaken by Motorola Inc., Sandia National Laboratory and Los Alamos National Laboratory. This work is being accomplished as part of a cooperative research and development agreement (CRADA) under the Department of Energy (DOE) Industrial Waste Reduction Program. The objective was to evaluate the new self-cleaning soldering process and to prove that hardware produced by the process is acceptable for military applications. The breakdown of tasks under the CRADA is as follows: Motorola supplied the self-cleaning soldering hardware, PWB test bed manufacturing and some of the environmental testing; SNLA provided most of the environmental testing and statistical analysis of the component electronic reliability data; and LANL provided the analytical determinations of surface cleanliness and materials compatibility. The data from these tests will be used to support approvals of the process for military hardware applications.

The experimental approach and testing methods employed by LANL personnel are described herein. A detailed listing and discussion of the SNLA and Motorola portions of this program are not described in this report; these details can be found in the complete project result document. 1 This document is organized into the following sections: (a) background descriptions of the known procedural and chemical details of the self-cleaning soldering process, (b) analytical results of each aspect of the surface cleanliness program preceded by a brief description of the analytical method and information gained, (c) summary of the results obtained, and (d) suggestions regarding future work.

\section{BACKGROUND ON THE SELF-CLEANING SOLDER PROCESS}

Several self-cleaning soldering processes that have been developed over the past few years. ${ }^{2-4}$ The specific process utilized in this study deploys an ultrasonic spray of dilute adipic acid boardpreparation solution over the advancing PWB coupled with a formic acid vapor in a nitrogen cover blanket extending into the soldering zone. This board preparation precedes the soldering process, and thermal heat from the soldering process may largely degrade these chemical components into innocuous by-products.

Adipic acid $\left(\mathrm{C}_{6} \mathrm{O}_{4} \mathrm{H}_{10}\right)$ is a white, crystalline dicarboxylic acid that is dissolved in anhydrous isopropyl alcohol for use as a flux. The typical concentration for use as a board-preparation material ranges from $1 \%$ to $3 \%$. The material has been used in commercial electronics assembly for several years, generally in modes that have not used cleaning after wave soldering operations. These applications range from under-hood automotive applications to cellular radio communications.

The physical and chemical properties of adipic acid have been evaluated to characterize the effects of the material after wave soldering. 5 Most of the adipic acid is consumed by thermal decomposition during the soldering process. At the end of the process, only a small percentage of the original material remains on the PWB. The adipic acid reduces the tin and lead oxides on the surface of the 
solder during the preheat stage, just as normal rosin fluxes do. During preheat a small amount of the adipic acid is driven off and condenses on the cooler surfaces of the machine. Adipic acid is also driven off the PWB by thermal heat transfer during the wave soldering operation.

Formic acid vapor is added to the process by bubbling nitrogen through a liquid formic acid solution. The amount of formic acid vapor introduced to the machine is governed by the nitrogen gas flow rate. The formic acid in the nitrogen cover blanket acts as an oxygen getter, thereby further reducing oxide formation in the soldering zone. The heat supplied in the soldering process thermally decomposes formic acid into $\mathrm{CO}_{2}$ and $\mathrm{H}_{2} \mathrm{O}$. An additional benefit of the inert atmosphere is the reduction of dross on or in the solder pot.

The analytical portions of the testing focus on confirming the presence (or nonexistence) of specific residues of adipic and formic acid and on assessing the role that they play in the long term stability of the PWB's components. From a logistic point of view, the analytical methodology proceeded initially with nondestructive techniques followed by methodologies requiring smaller physical samples and destructive sample preparation. Specifically the testing proceeded with highperformance liquid chromatography (HPLC) techniques, followed by infrared spectroscopic (IR) and optical micrographic examinations. None of these techniques required modification of the test PWBs. The next set of analytical determinations consisted of electron microprobe analysis, secondary ion mass spectroscopy (SIMS- both quadruple and time-of-flight mass selection), and occasionally scanning Auger electron spectroscopy (AES). Because of the vacuum requirements inherent to these techniques, PWB sample preparation required destructive sectioning.

ANALYTICAL RESULTS

Motorola Test Board - Surface Analysis

The Motorola test board (MTB) is a nonfunctional test board that was surveyed for free and complexed chemical residues using several techniques. These techniques included HPLC analysis for conventional solder flux residues and free adipic acid, a 1,1,2 - trichlorotrifluoroethane board rinse followed by an infrared examination of the $\mathrm{C}-\mathrm{H}$ region of the eluant for total hydrocarbon and grease determination, small-area $\left(10^{2}-10^{4} \mathrm{~mm}^{2}\right)$ optical microscopy and FTIR examination of deposits atop solder pads, and time-of-flight mass spectroscopic (TOFMS) examinations of solder residues on conventional and self-cleaned soldered portions of these PWBs. The purpose of these examinations was to assess whether process contamination leads to any degradation or observable differences in performance parameters between test cells in the long-term testing of the International Printed Circuit (IPC) B-24 and FMU-139 boards.

It might be expected that the self-cleaning solder process might result in incomplete removal of adipic and formic acids. Furthermore, salts of lead and tin with adipic and formic acid might be present along with partially degraded adipic and formic acid by-products. These analytical determinations were pursued to assess the level of surface contamination and the chemical nature of the material left after the self-cleaning. In addition, these examinations verified that solder rosin flux was effectively removed (as expected) from the control set of conventional soldered boards that were solvent-cleaned according to conventional military specifications.

The HPLC analysis procedure was closely based on the IPC Honeywell 355 method $^{8}$ for determination of conventional solder residue components (for example, abietic and neoabietic acids). Although this procedure works well for conventional solder fluxes, the uncomplexed formic and adipic acids are only slightly soluble in the acetonitrile elution solvent. Regardless of this limitation, the modified procedure could effectively determine free (uncomplexed) adipic acid concentrations $\leq 40 \mathrm{mg} \mathrm{cm}^{-2}$. Eighteen boards were examined before environmental testing, and free adipic acid levels were below detection limits for all boards. 
Total hydrocarbon and grease contamination levels were determined following an ASTM method that entailed washing the solder side of the MTB PWBs with 1,1,2 - trichlorotrofluoroethane and monitoring the absorbance of the $\mathrm{C}-\mathrm{H}$ stretch region in a $0.5-$ to $2.0-\mathrm{mm}$-path-length liquid IR cell. Only two of the nine boards examined exhibited any detectable hydrocarbon contamination, and these levels were below $2 \mathrm{mg} \mathrm{cm}^{-2}$.

Despite the inconclusive results that relied on removing potential contaminants from the PWBs, optical microscopy and small-area FTIR examination clearly indicated that nonmetallic residues were present on the MTBs. In Fig. 1, a representative IR spectrum is shown along with an optical micrograph from a small area of a MTB processed using the self-cleaning method. In general, the conventional rosin-flux soldered/solvent cleaned boards possess bright, clean solder joints, as is expected using a well-refined technology. The boards soldered using the self-cleaning process exhibited some white deposits around the edges of the solder lug bases and occasionally in the center of depressed, solder-filled printed via holes. These deposits are evident in the optical micrograph accompanying the IR spectrum. Although a detailed discussion of all the data sets obtained is beyond the scope of this report, several distinct IR features are worthy of mention. Most of the deposits examined exhibited a broad, featureless vibrational band from 3000 to $3600 \mathrm{~cm}^{-1}$ identified with the O-H stretch of adsorbed water, sharper bands in the 2900 to $3000 \mathrm{~cm}^{-1}$ region consistent with $\mathrm{C}-\mathrm{H}$ stretches, and a strong band at $1620 \pm 20 \mathrm{~cm}^{-1}$ assigned to a $\mathrm{C}=\mathrm{O}$ stretch. All of these spectral features are consistent with the presence of surface functionalities that arose from partial decomposition of carboxylic acids in the self-cleaning process (for example, formic and adipic acids). Small-area FTIR examination of the conventional rosin flux/solvent-cleaned boards revealed no measurable organic residue. IR spectra recorded from residues on the self-cleaned boards were noticeably different from reference spectra derived from free adipic and formic acid. This observation coupled with the inability to remove these crystalline deposits with the $1,1,2-$ trichlorotrofluoroethane wash procedure suggest that the deposits arise from partial thermal degradation product(s) of the adipic and/or formic acid vapor as the board moves from the selfcleaning process stream. The question remains as to the most appropriate global (for example, board wide or per $\mathrm{cm}^{-2}$ ) analytical measure of this hydrocarbon residue that would represent a meaningful measure of processing quality.

More specific confirmatory information regarding the chemical makeup of the residues left behind after self-clean solder operations was obtained following time-of-flight mass analysis (TOFMS) of selected MTBs. The specific MTBs analyzed included boards numbered MNS01C26 (self-cleaned solder process abbreviated MNS): and MNR01C16 (traditional solder/flux/chlorofluorohydrocarbon [CFC]-cleaned board abbreviated MNR). Each of these boards had FTIR spectra recorded from each of the solder pad regions examined by TOFMS. On the MNS board the presence of carboxylate residues left behind as a result of the self-cleaned solder process was clearly identified in the IR data. Both positive and negative ion spectra were recorded up to mass 600 . Positive ion spectra from solder pads on the MNR and MNS boards contained prominent $\mathrm{Sn}^{+}, \mathrm{Pb}^{+}$, and low-mass hydrocarbon peaks. The $\mathrm{C}^{+}$peak at mass 12.00 was more intense in spectra from board MNR, whereas the adventitious hydrocarbon peaks (masses $\mathrm{C}_{\mathrm{X}} \mathrm{H}_{2 \mathrm{x}}$ ) were more intense from board MNS. Polydimethylsiloxane (PDMS) was present on solder pad regions on both MNS and MNR boards, although at higher intensity on the MNS board. PDMS is used as a mold-release agent in plastic and presumably PWB manufacturing processes. The implication of higher PDMS concentration on the MNS board is presumably a consequence of the CFC cleaning step that removes some (if not most) of this agent. The negative ion spectra of both of these samples contained prominent $\mathrm{F}^{-}$peak identifiers with the peak more intense on the MNS board. Various fluorocarbon mass identifiers and $\mathrm{Br}^{-}$were observed in spectra from solder pads regions on both the MNR and MNS boards. Generally, peaks above 200 were more intense from the MNR board. Parent peaks for adipate ion were not observed form the MNS solder pad regions. However, carboxylate fragmentation mass ions $\left(\mathrm{C}_{2} \mathrm{HO}^{-}[\mathrm{m} / \mathrm{e}=41.00], \mathrm{CHO}_{2}^{-}[\mathrm{m} / \mathrm{e}=45.00], \mathrm{C}_{2} \mathrm{H}_{2} \mathrm{O}_{2}^{-}[\mathrm{m} / \mathrm{e}=58.01], \mathrm{C}_{3} \mathrm{H}_{3} \mathrm{O}_{2}^{-}[\mathrm{m} / \mathrm{e}=\right.$ 


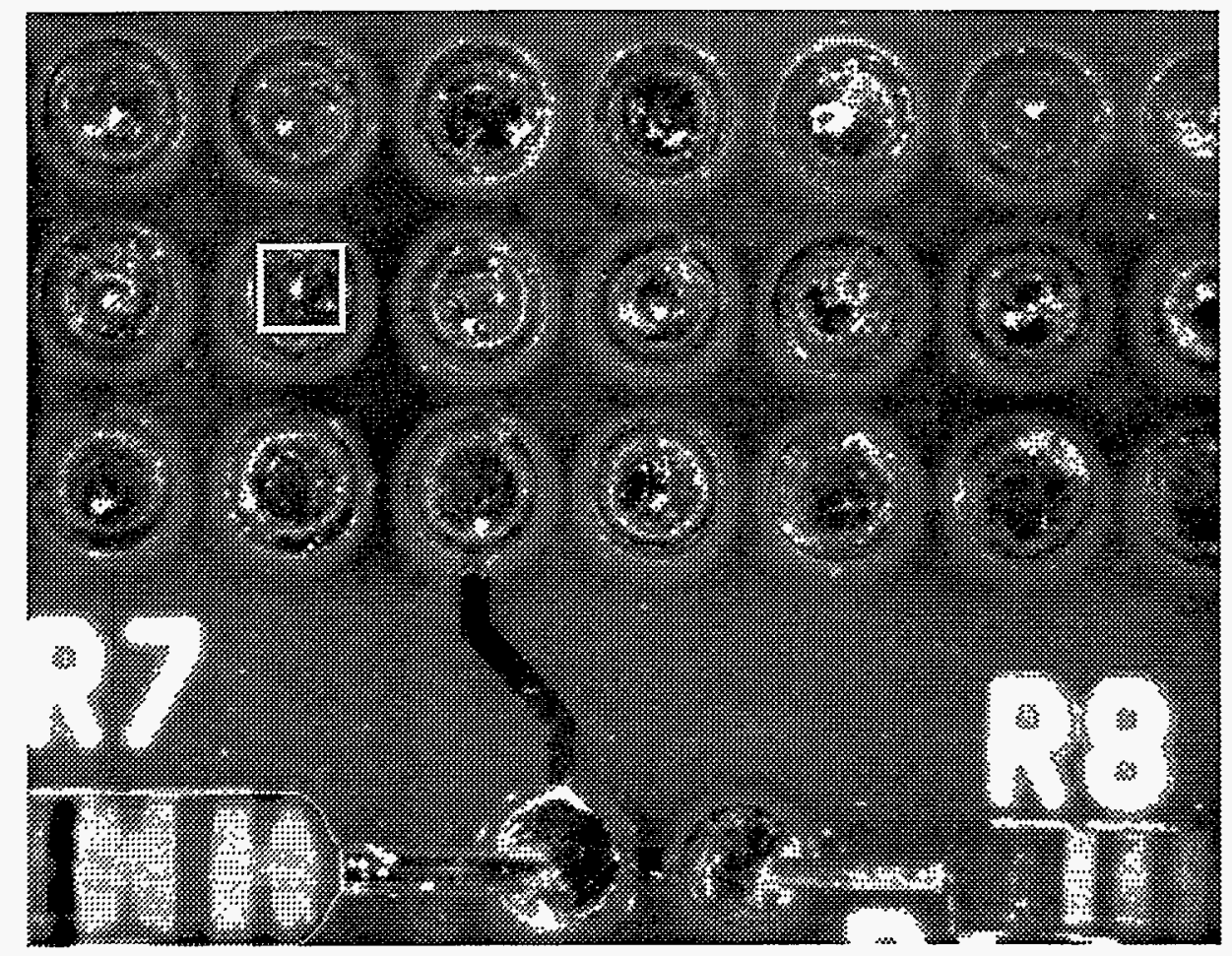

Fig. 1a. Photomicrograph of Motorola test board at $4 \mathrm{x}$ magnification. Highlighted region expanded 40x below and is representative of IR data shown in Fig. 1c.

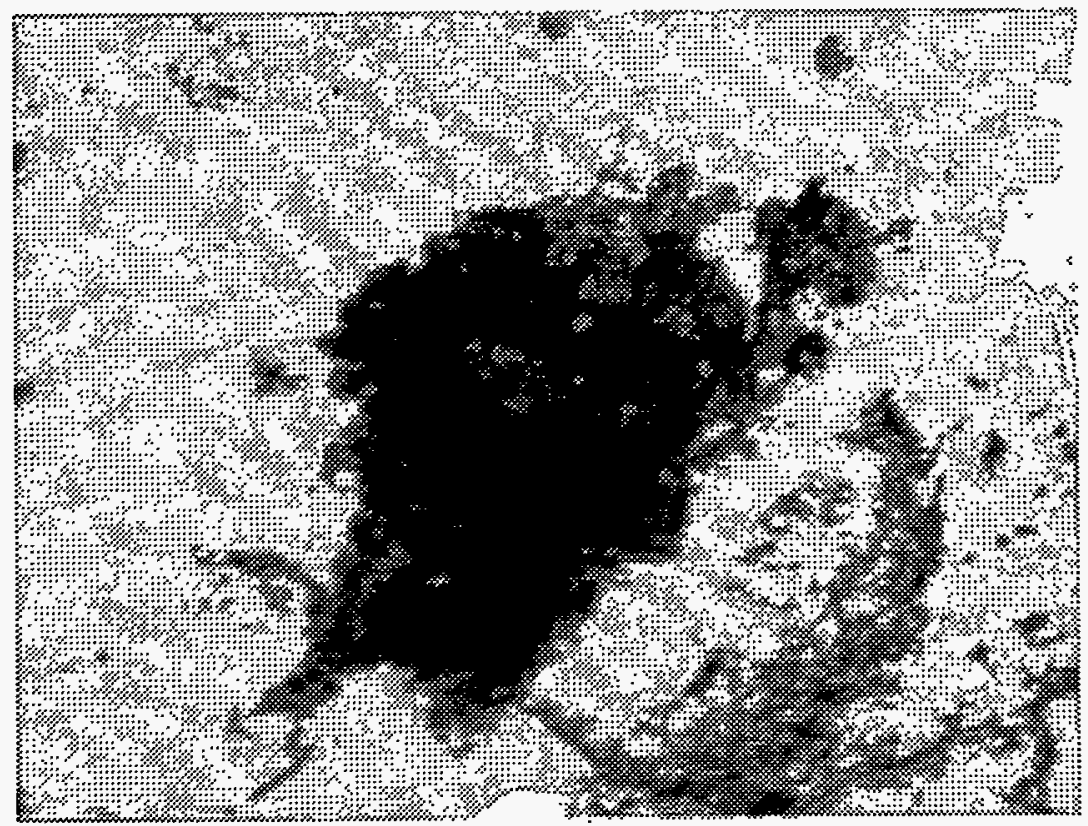

Fig. 1b. Photomicrograph of region highlighted in Fig. 1a. 


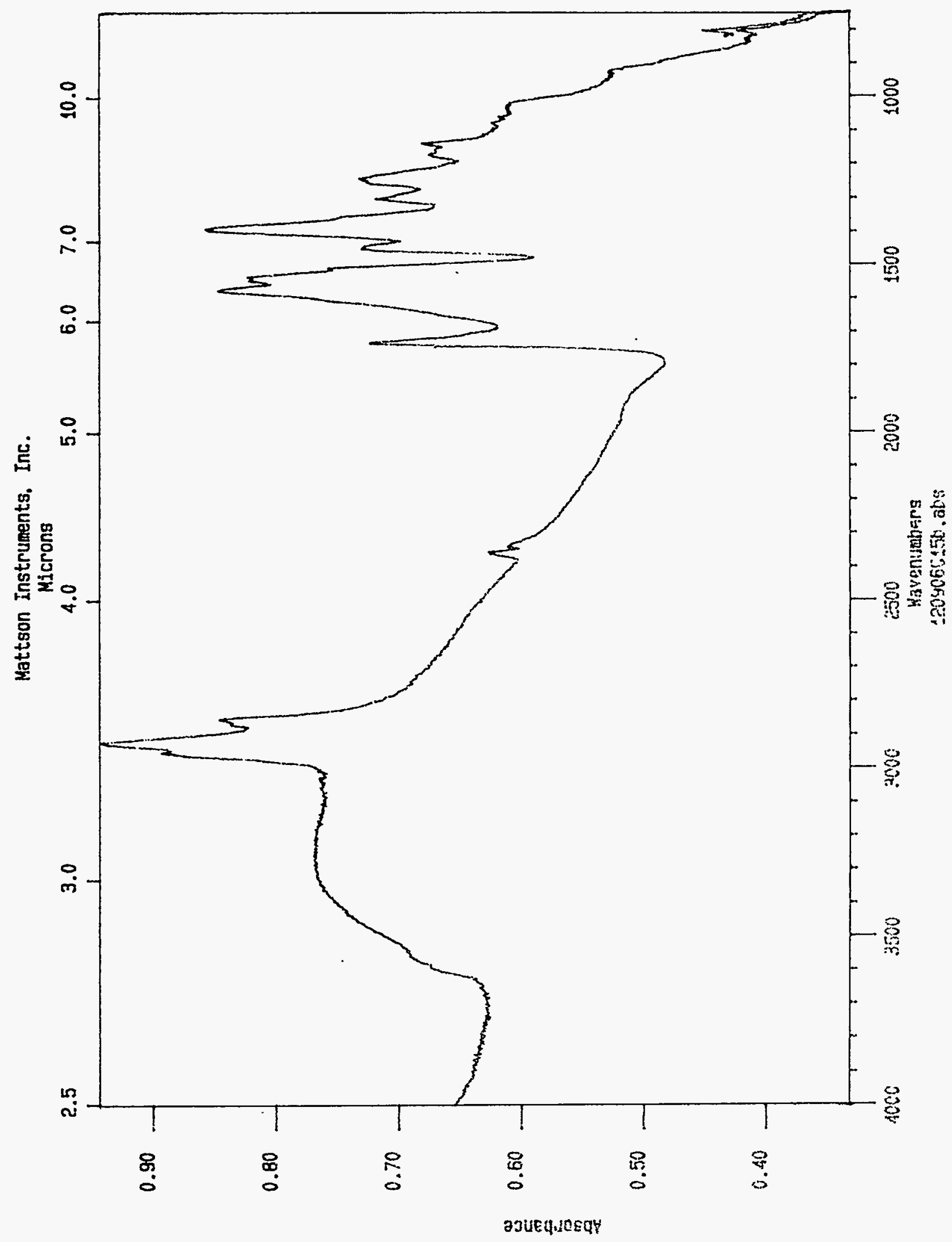

Fig. 1c. Infrared spectrum from photomicrograph shown in Fig. 1b. 
71.01], were readily observed from all the solder pad regions on board MNS. Intensities of these carboxylate ion fragments were much lower (or nonexistent) from the MNR board solder pad regions. Representative spectra from both positive and negative ion mass ranges are shown in Figs. 2 and 3 for the MNS board solder pad region and Figs. 4 and 5 for the MNR board solder pad region. Accompanying tables are given beneath each figure that display mass spectral assignments. Fig. 6 is a photomicrograph of the representative, identical solder pad region from both boards. In summary, carboxylate decomposition products were readily observed at solder bond pad regions from the self-cleaned-process PWB but not on the traditional solder/flux/CFC-cleaned PWB solder bond pads.

\section{Comb Pattern Board - Surface Analysis}

A set of six IPC B-24 surface-insulation resistance (SIR) PWBs were examined following temperature-humidity testing to determine the chemical residues and to assess whether these residues reflect differences between SIR test cell results. The SIR boards examined were those that displayed lowered resistance values during and at the end of the temperature-humidity environmental testing program. The analytical procedure began with photomicroscopy followed by electron microprobe analysis (EMPA), SIMS, and scanning AES of selected target areas of the less desirable SIR PWBs. Only a representative case will be discussed but in general the six less desirable SIR boards all had regions of similar surface corrosion and contamination.

In Fig. 7, a photomicrograph of a portion of the SIR board is shown along with SIMS elemental maps of elemental contaminants of one of the corrosion deposits. The elemental image maps clearly show the inhomogeneous presence of lead and tin. Copper and potassium are evident as well as a number of common impurities (sodium and calcium not shown) that are typically found following water evaporation. Of note is the increase in the lead ion yield over a specific region of the solder runner and a decrease in the tin ion yield in the same region. The SIR PWBs that displayed these corrosion deposits always had some level of copper underneath or mixed in with a rather thick (many micrometers deep) mixed lead and tin oxide layer. Frequently the lead and tin oxide regions were found between the comb runners with the lead in greater chemical abundance than found in the source solder. Remnant moisture from ambient air or residual from the humidity chamber testing would lead to noticeably lower resistance values or even a potential electrical short. Assuming that the SIR boards did not possess any observable gross initial defects, the source of the deposits is most likely the process water contamination level at the end of the test and the environmental chamber surfaces with which it came into contact during testing.

Visual examination of the six affected SIR PWBs clearly indicated that section A of the IPC B-24 board had the highest density of corrosion defects. The fact that this portion of the test board was typically run with an applied potential suggests that the predominant mode of corrosion deposits was driven by an electrochemical process. Unfortunately, the self-cleaned solder process and conventional rosin flux/solvent-cleaned SIR boards were simultaneously run in the environmental test chamber. It is thus impossible to assess whether the observed corrosion deposits were influenced by adipic and formic acid residues being picked up and transported in the humidity water. In fact, one of the rosin flux/solvent-cleaned SIR boards displayed a prominent corrosion short of chemical composition similar to that shown in Fig. 7 for a self-cleaned soldered board.

\section{Eunctional Test Board-Surface Analvsis}

A set of four FMU-139 boards were examined for chemical residues following environmental temperature and humidity testing at the Motorola plant. This set of boards was selected on the basis of the poor visual appearance and in some cases poor electrical performance following environmental testing. In all cases the suspect portion of the board was centered around a particular diode type. Other boards clearly displayed evidence of water dripping down one side of the PWB. Figure 8 shows a photomicrograph of the region of the PWB with the suspect diode. Note the obvious 


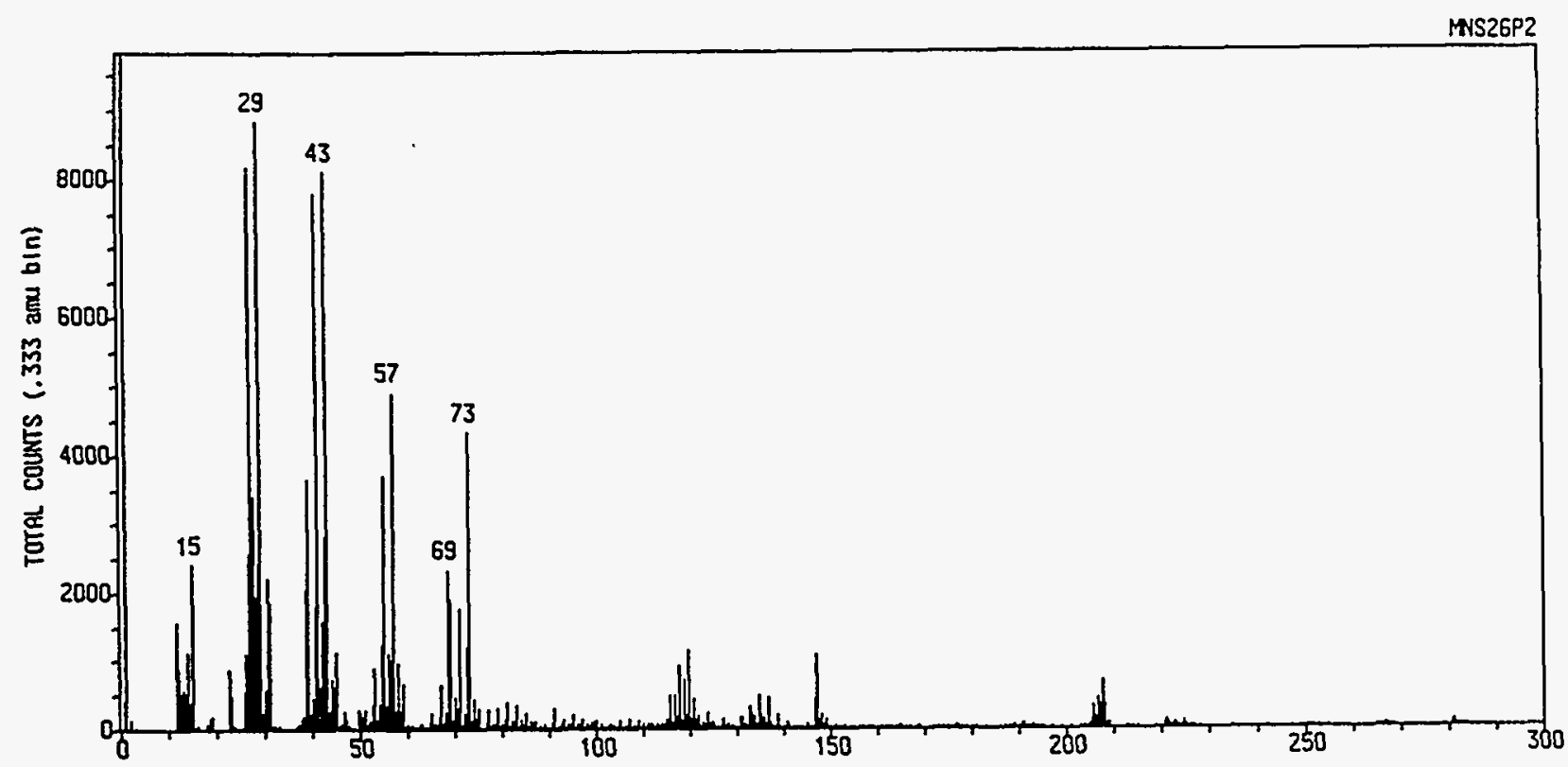

Fig. 2. TOF mass spectrum, positive ions $0-300 \mathrm{~m} / \mathrm{z}$, MNS board.

Table I

Positive Ion Mass Assignments

\begin{tabular}{|c|c|c|c|}
\hline $\begin{array}{r}34125 \\
9484 \\
10552 \\
14561 \\
1520 \\
12922 \\
2983 \\
968 \\
8683 \\
50216 \\
23705 \\
44857 \\
2298 \\
10692 \\
1570 \\
29820 \\
5209 \\
36154 \\
6862 \\
35006 \\
2340 \\
7615 \\
679 \\
992 \\
1228 \\
633 \\
4260 \\
1515 \\
15918 \\
3690 \\
21542 \\
3071 \\
4049\end{array}$ & $\begin{array}{l}11.9808 \\
12.9950 \\
14.0076 \\
15.0219 \\
18.9979 \\
22.9860 \\
23.9713 \\
24.9873 \\
26.0139 \\
27.0259 \\
27.9694 \\
29.0426 \\
30.0326 \\
31.0058 \\
38.0171 \\
39.0155 \\
39.9991 \\
41.0505 \\
42.0501 \\
43.0617 \\
44.0529 \\
45.0490 \\
46.9938 \\
50.0100 \\
51.0333 \\
52.0392 \\
53.0501 \\
54.0566 \\
55.0704 \\
56.0802 \\
57.0932 \\
58.0880 \\
59.0731\end{array}$ & $\begin{array}{l}0.9439 \\
0.2623 \\
0.2919 \\
0.4027 \\
0.0420 \\
0.3574 \\
0.0825 \\
0.0268 \\
0.2402 \\
1.3889 \\
0.6557 \\
1.2407 \\
0.0636 \\
0.2957 \\
0.0436 \\
0.8248 \\
0.1441 \\
1.0000 \\
0.1898 \\
0.9682 \\
0.0647 \\
0.2106 \\
0.0188 \\
0.0274 \\
0.0340 \\
0.0175 \\
0.1178 \\
0.0419 \\
0.4403 \\
0.1021 \\
0.5958 \\
0.0849 \\
0.1120\end{array}$ & $\begin{array}{l}\text { C } \\
\text { CH } \\
H \\
\text { CH3 } \\
\text { F } \\
\text { Ha } \\
\text { C2 } \\
\text { C2H } \\
\text { C2H2 } \\
\text { C2H3 } \\
\text { Si } \\
\text { C2H5 } \\
\text { CH4H } \\
\text { HHO } \\
\text { C3H2 } \\
\text { C2HH } \\
\text { C2O } \\
\text { C3H5 } \\
\text { C3H6 } \\
\text { C3H7 } \\
\text { C2H6H } \\
\text { CH5H2 } \\
\text { KHO2 } \\
\text { C4H2 } \\
\text { C4H3 } \\
\text { C4H4 } \\
\text { C4H5 } \\
\text { C4H6 } \\
\text { C4H7 } \\
\text { C4H8 } \\
\text { C4H9 } \\
\text { C4H1O } \\
\text { C3HOH }\end{array}$ \\
\hline
\end{tabular}

$\begin{array}{rrrl}605 & 65.0645 & 0.0167 & \text { CSH5 } \\ 2237 & 67.0844 & 0.0619 & \text { C5H7 } \\ 766 & 68.0796 & 0.0212 & \text { CSH8 } \\ 8458 & 68.9140 & 0.2339 & \text { Ga } \\ 5342 & 69.0845 & 0.1478 & \text { C5H9 } \\ 6173 & 71.1190 & 0.1707 & \text { C5H11 } \\ 735 & 72.1032 & 0.0203 & \text { C5H12 } \\ 8781 & 73.0947 & 0.2429 & \text { C4H11H } \\ 792 & 74.0935 & 0.0219 & \text { C4H12H } \\ 725 & 75.0674 & 0.0201 & \text { C3H9HO } \\ 747 & 77.0683 & 0.0207 & \text { C2HSH2O } \\ 726 & 79.0836 & 0.0201 & \text { C6H7 } \\ 1197 & 81.1032 & 0.0331 & \text { C6H9 } \\ 1115 & 83.1168 & 0.0308 & \text { C6H11 } \\ 720 & 85.1182 & 0.0199 & \text { C6H13 } \\ 752 & 87.0888 & 0.0208 & \text { C4H11H2 } \\ 696 & 91.1003 & 0.0193 & \text { C3H11H2O } \\ 581 & 95.1211 & 0.0161 & \text { C7H11 } \\ 3036 & 115.8839 & 0.0840 & 116 S n \\ 2644 & 116.8919 & 0.0731 & 117 S n \\ 5669 & 117.8826 & 0.1568 & 118 S n \\ 3415 & 118.8905 & 0.0945 & 119 S n \\ 7060 & 119.8846 & 0.1953 & \text { Sn } \\ 2058 & 120.9098 & 0.0569 & \text { HSn } \\ 866 & 121.8779 & 0.0240 & 122 S n \\ 1202 & 123.8849 & 0.0332 & 124 S n \\ 1240 & 132.9928 & 0.0343 & \text { C7HO3 } \\ 1204 & 134.9277 & 0.0333 & \text { H3H118Sr } \\ 1287 & 136.9253 & 0.0356 & \text { CH3122Sn } \\ 2239 & 147.1787 & 0.0619 & \text { C7H19N2O } \\ 3486 & 205.9668 & 0.0964 & 206 P b \\ 3734 & 206.9861 & 0.1033 & 207 P b \\ 7291 & 207.9709 & 0.2017 & \text { Pb } \\ & & & \end{array}$




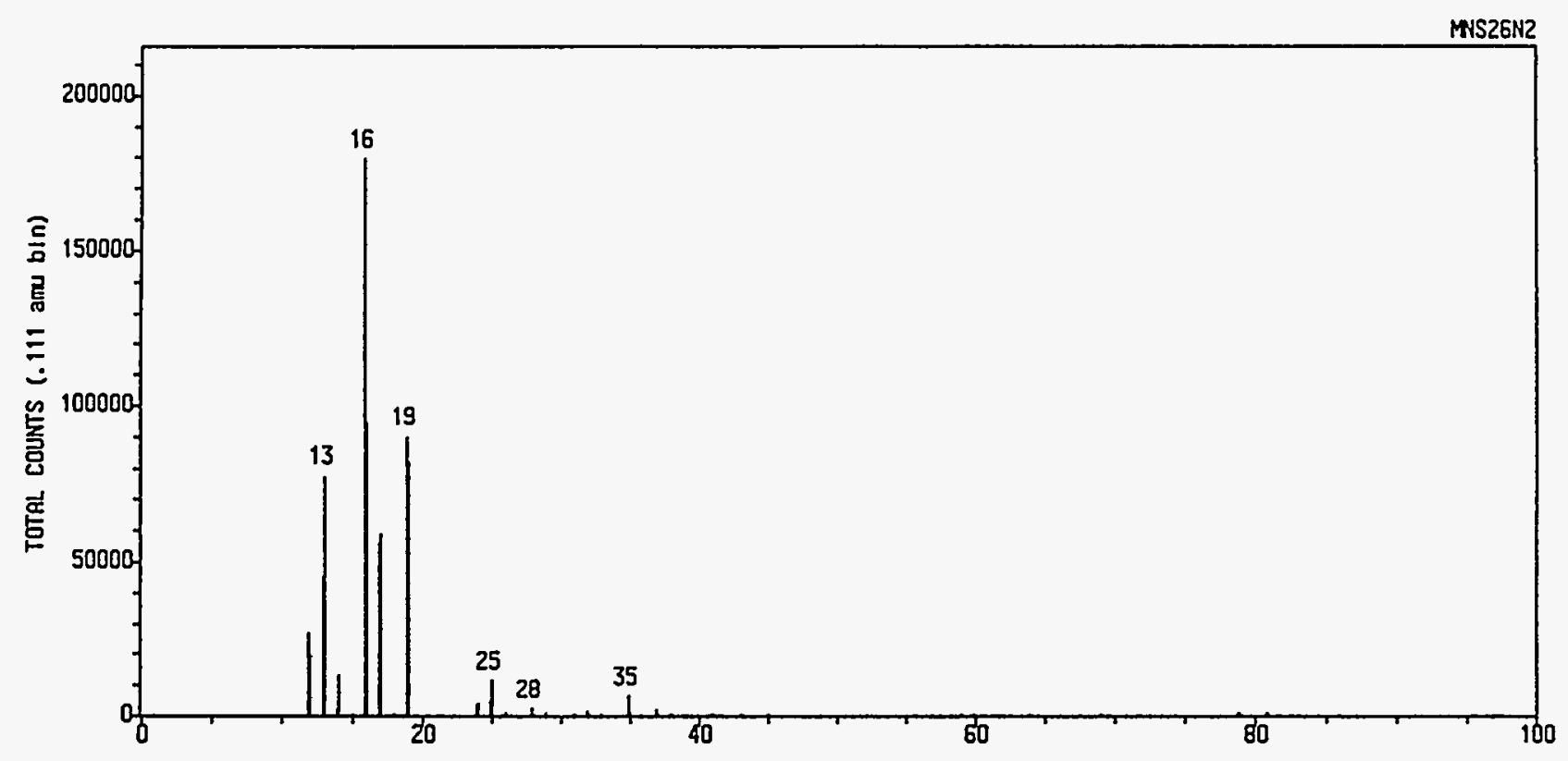

Fig. 3a. TOF mass spectrum, negative ions $0-100 \mathrm{~m} / \mathrm{z}$, MNS board.

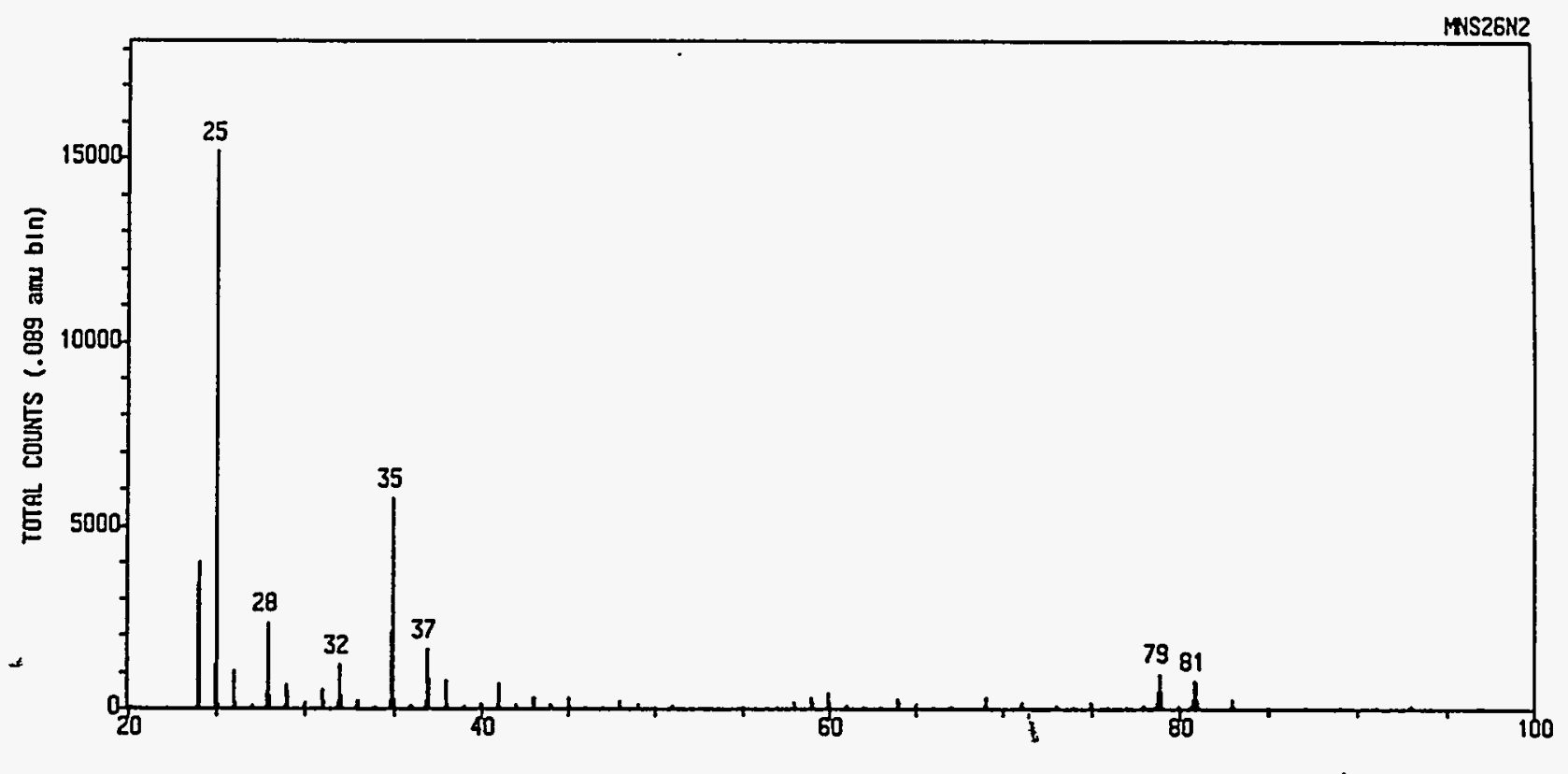

Fig. 3b. TOF mass spectrum, negative ions $20-100 \mathrm{~m} / \mathrm{z}$, MNS board. 


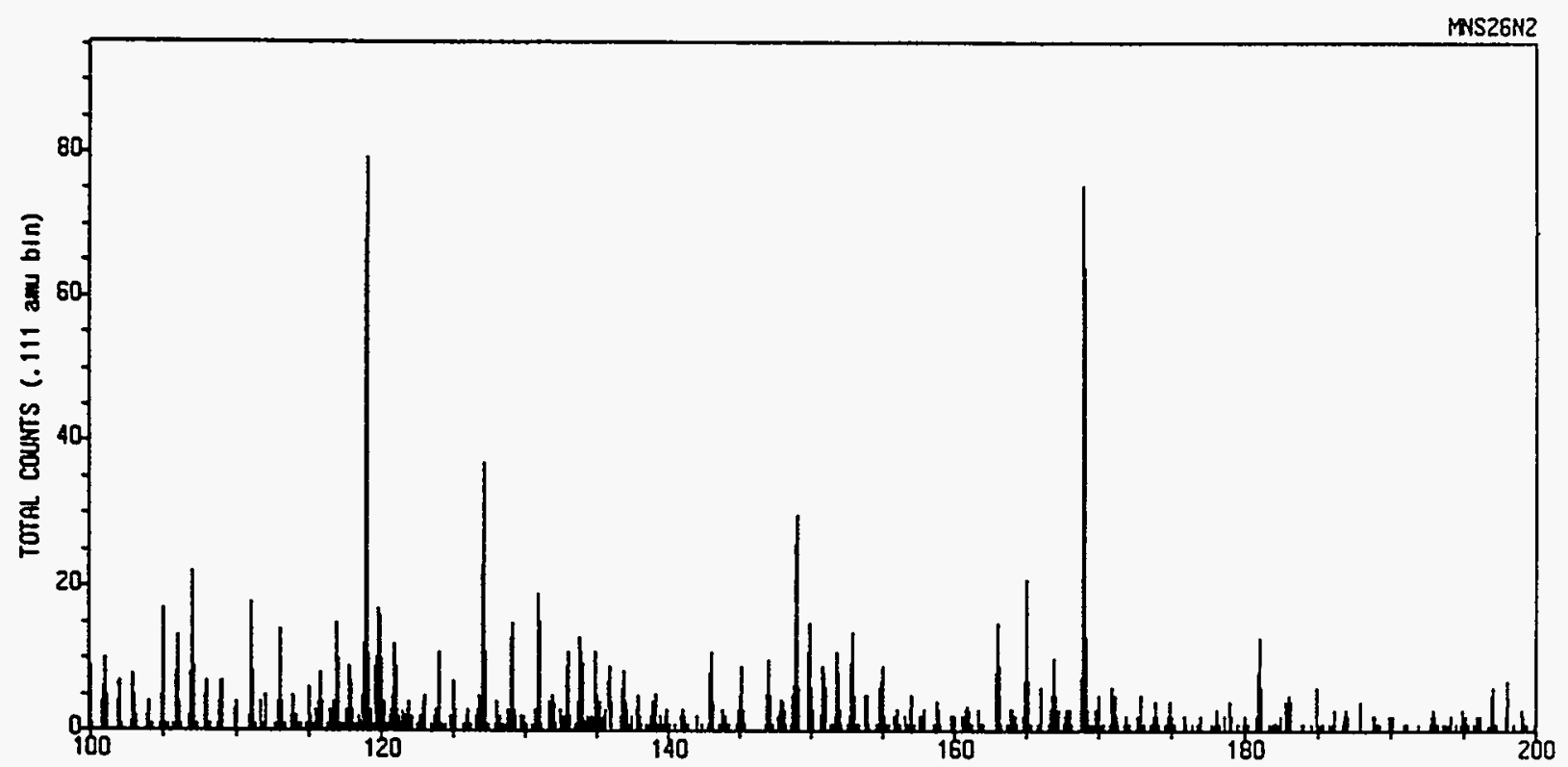

Fig. 3c. TOF mass spectrum, negative ions $100-200 \mathrm{~m} / \mathrm{z}$, MNS board.

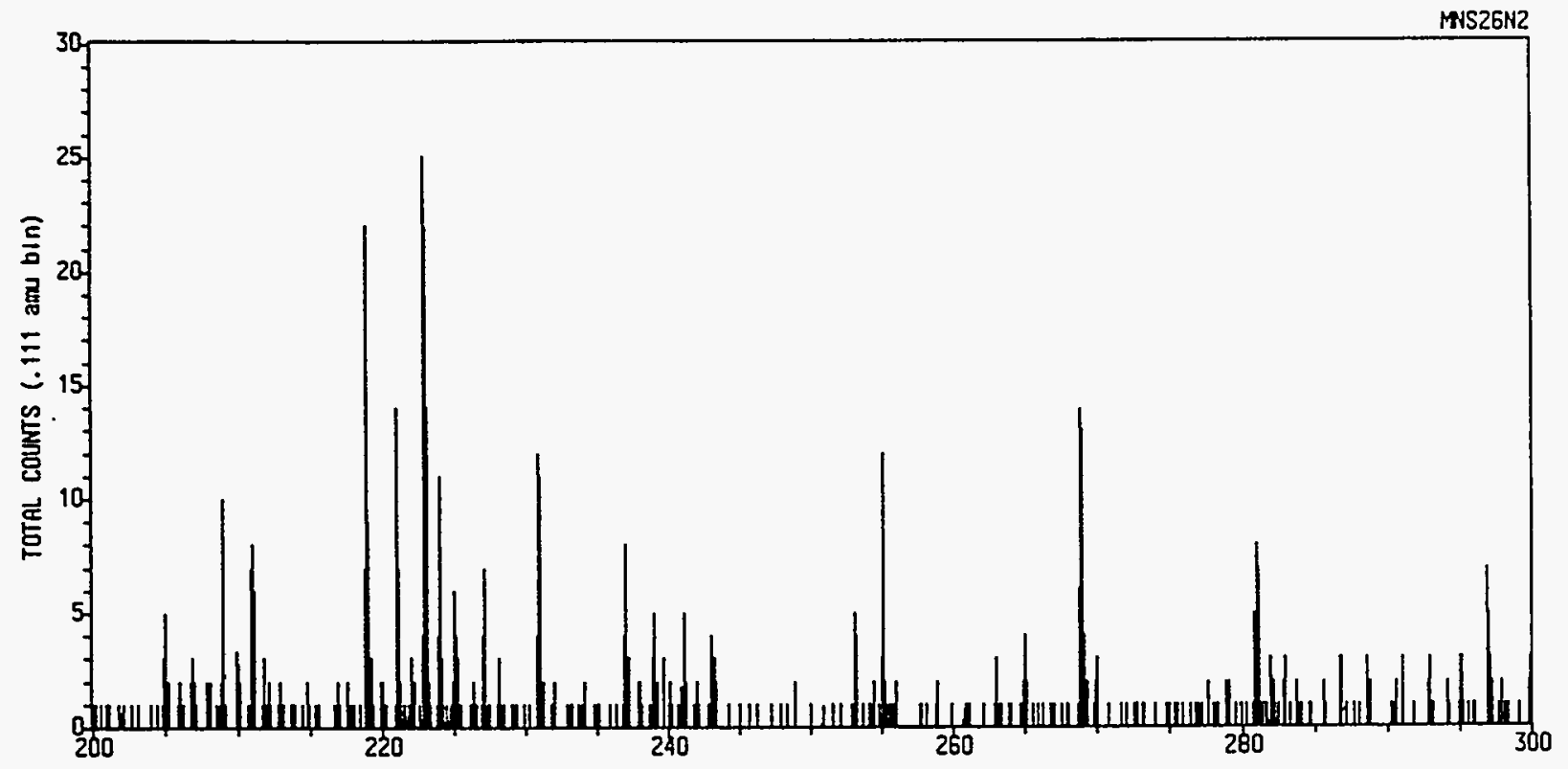

Fig. 3d. TOF mass spectrum, negative ions $200-300 \mathrm{~m} / \mathrm{z}$, MNS board. (See Table III for representative mass assignments for Figs. 3a-d. 


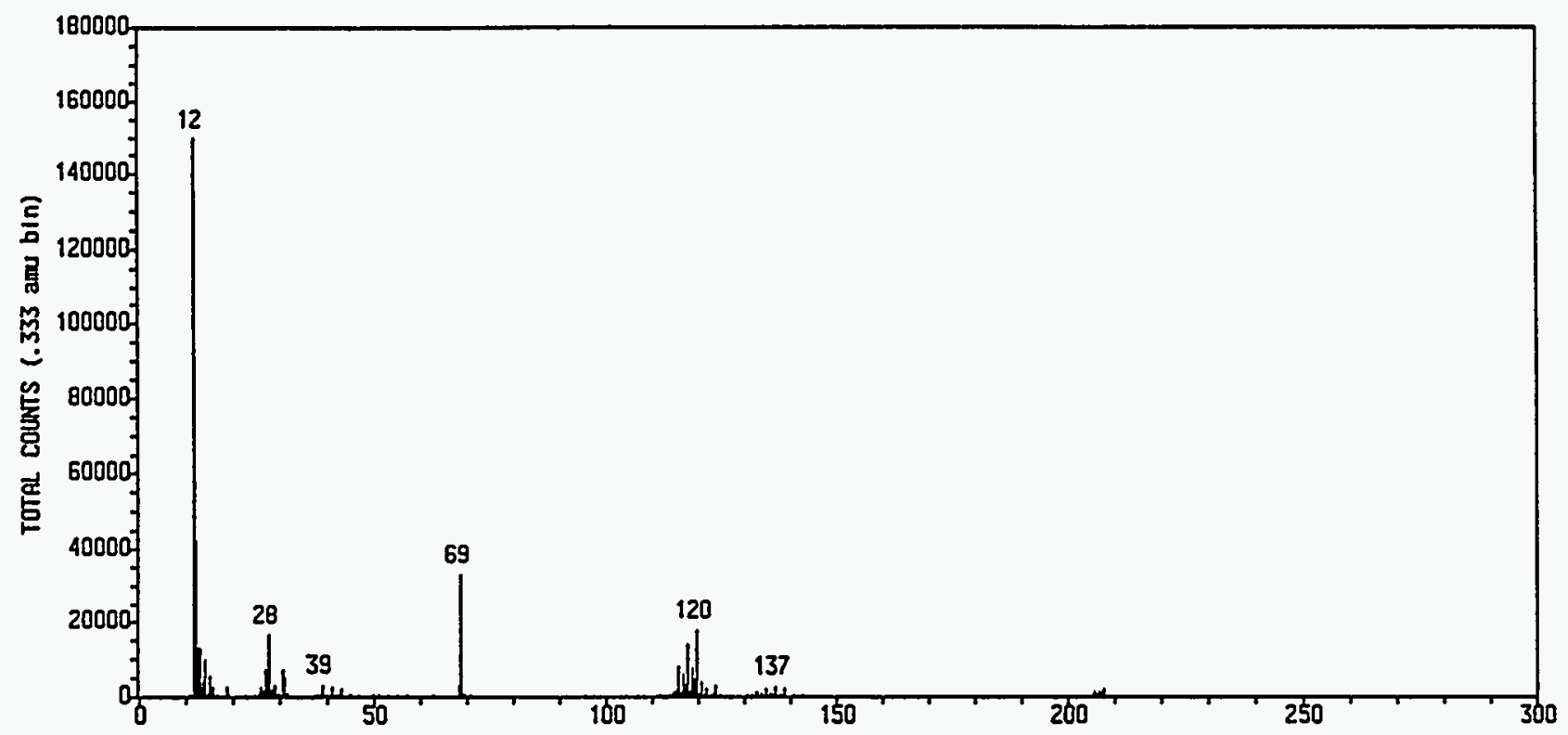

Fig. 4. TOF mass spectrum, positive ions $\mathrm{m} / \mathrm{z}$ 0-300, MNR board.

Table II

Positive Ion Mass Assignments

\begin{tabular}{|c|c|c|c|}
\hline $\begin{array}{r}\text { Intensity } \\
\text { [counts] } \\
627 \\
176437 \\
24895 \\
13513 \\
5982 \\
2458 \\
3387 \\
3484 \\
7623 \\
17112 \\
5960 \\
12090 \\
599 \\
3776 \\
2836 \\
757 \\
2767 \\
793 \\
668 \\
130 \\
405 \\
33034 \\
649 \\
1235 \\
8656 \\
6337 \\
14945 \\
7541 \\
21879 \\
3780 \\
2589 \\
3270 \\
766 \\
2224 \\
915 \\
2815 \\
2220 \\
1777 \\
1580 \\
3341 \\
213\end{array}$ & $\begin{array}{r}\text { Mass } \\
\text { tamu] } \\
10.9984 \\
11.9854 \\
12.9996 \\
14.0112 \\
15.0233 \\
15.9632 \\
18.9838 \\
26.0130 \\
27.0260 \\
27.9566 \\
28.9986 \\
30.9930 \\
38.0109 \\
39.0222 \\
41.0403 \\
42.0232 \\
43.0262 \\
49.9974 \\
55.0534 \\
55.8932 \\
57.0571 \\
68.8704 \\
111.8670 \\
114.8694 \\
115.8626 \\
116.8727 \\
117.8663 \\
118.8778 \\
119.8659 \\
120.8869 \\
121.8663 \\
123.8689 \\
133.9128 \\
134.9166 \\
135.9095 \\
136.9130 \\
138.8908 \\
205.9599 \\
206.9653 \\
207.9510 \\
226.9214\end{array}$ & $\begin{array}{r}\text { Horm. Int. } \\
0.2211 \\
62.2133 \\
8.7782 \\
4.7648 \\
2.1093 \\
0.8667 \\
1.1943 \\
1.2285 \\
2.6879 \\
6.0339 \\
2.1016 \\
4.2630 \\
0.2112 \\
1.3315 \\
1.0000 \\
0.2669 \\
0.9757 \\
0.2796 \\
0.2355 \\
0.0458 \\
0.1428 \\
11.6481 \\
0.2288 \\
0.4355 \\
3.0522 \\
2.2345 \\
5.2697 \\
2.6590 \\
7.7147 \\
1.3329 \\
0.9129 \\
1.1530 \\
0.2701 \\
0.7842 \\
0.3226 \\
0.9926 \\
0.7828 \\
0.6266 \\
0.5571 \\
1.1781 \\
0.0751\end{array}$ & 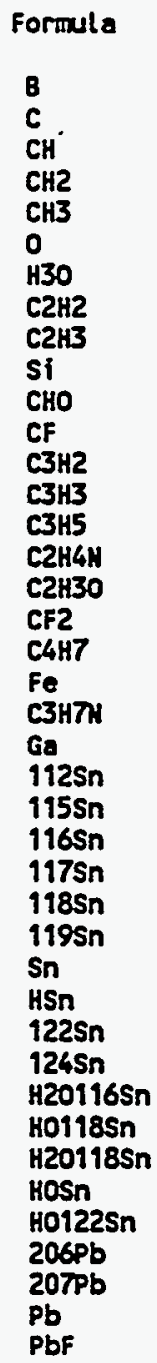 \\
\hline
\end{tabular}




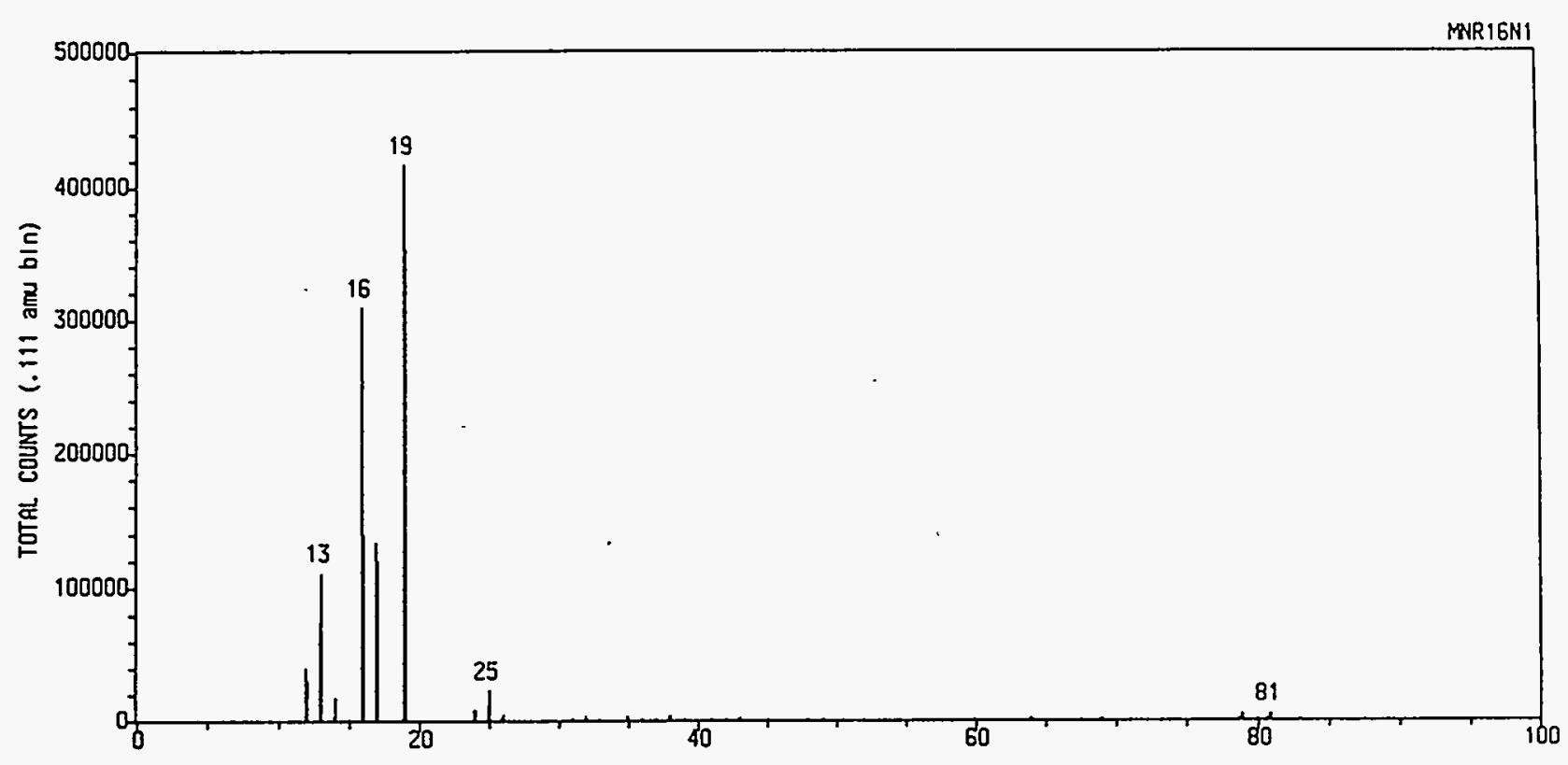

Fig. 5a. TOF mass spectrum, negative ions $\mathrm{m} / \mathrm{z}$ 0-100, MNR board.

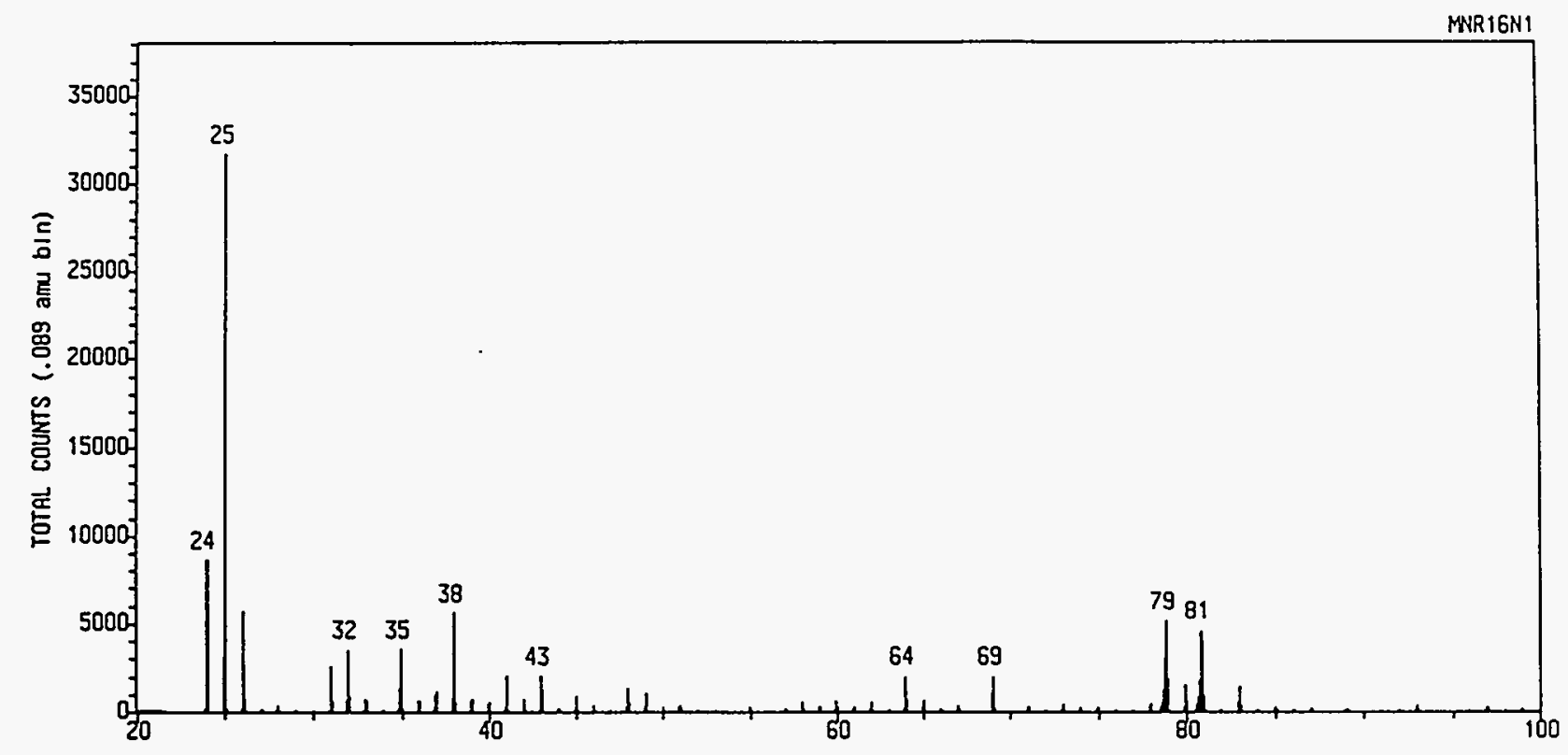

Fig. 5b. TOF mass spectrum, negative ions $\mathrm{m} / \mathrm{z}$ 20-100, MNR board. 


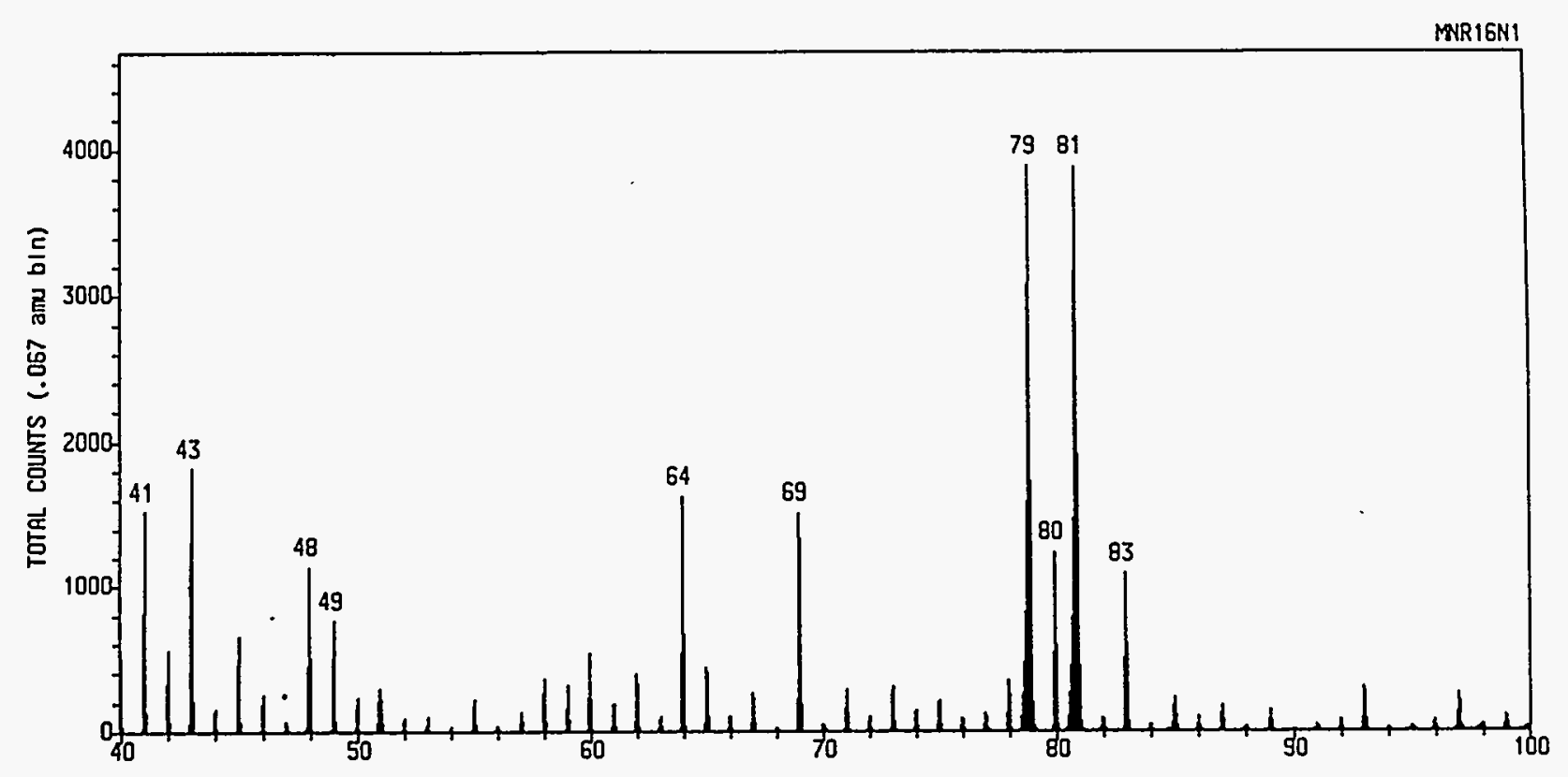

Fig. 5c. TOF mass spectrum, negative ions $40-100 \mathrm{~m} / \mathrm{z}$, MNR board.

MRRIGNI

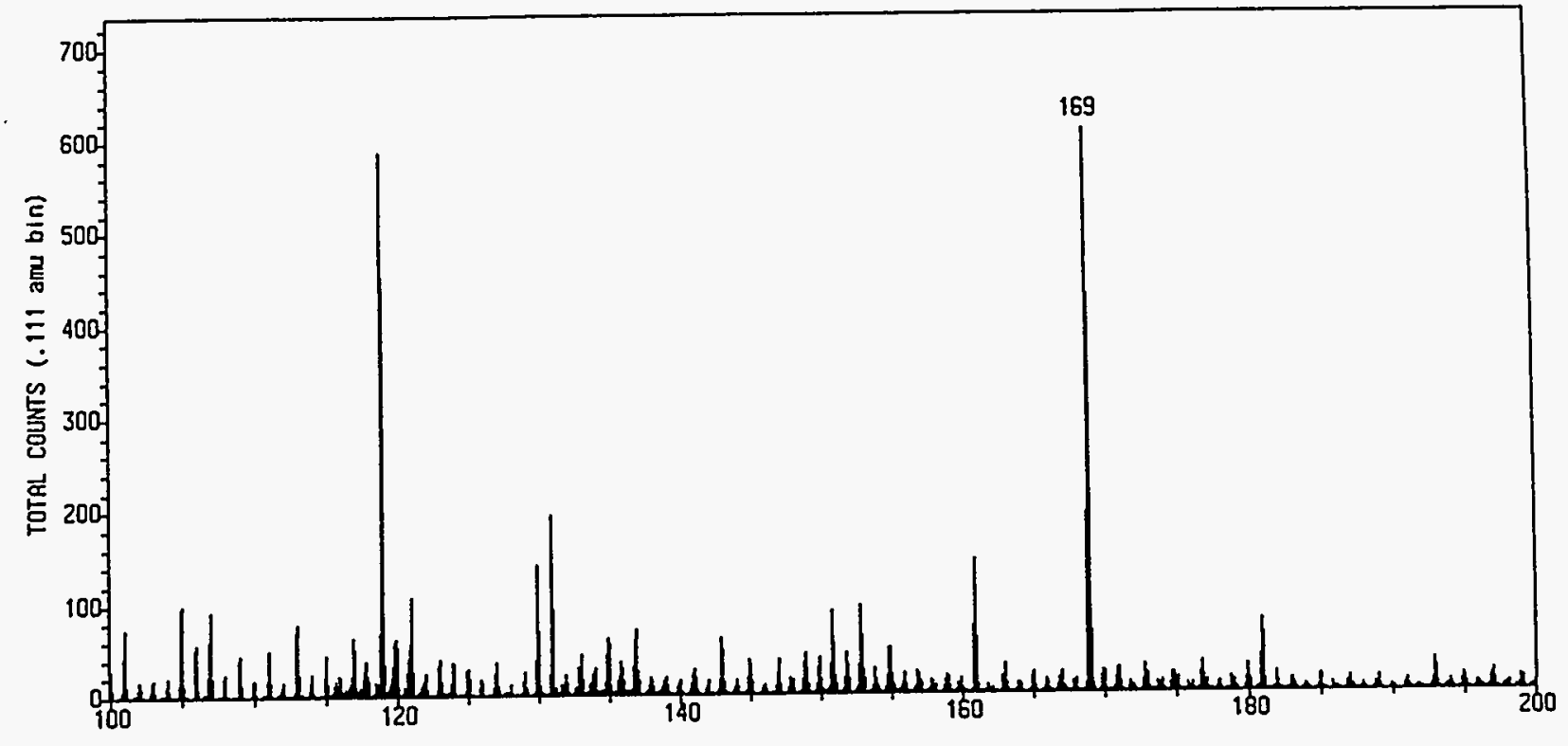

Fig. 5d. TOF mass spectrum, negative ions $100-200 \mathrm{~m} / z$, MNR board. 


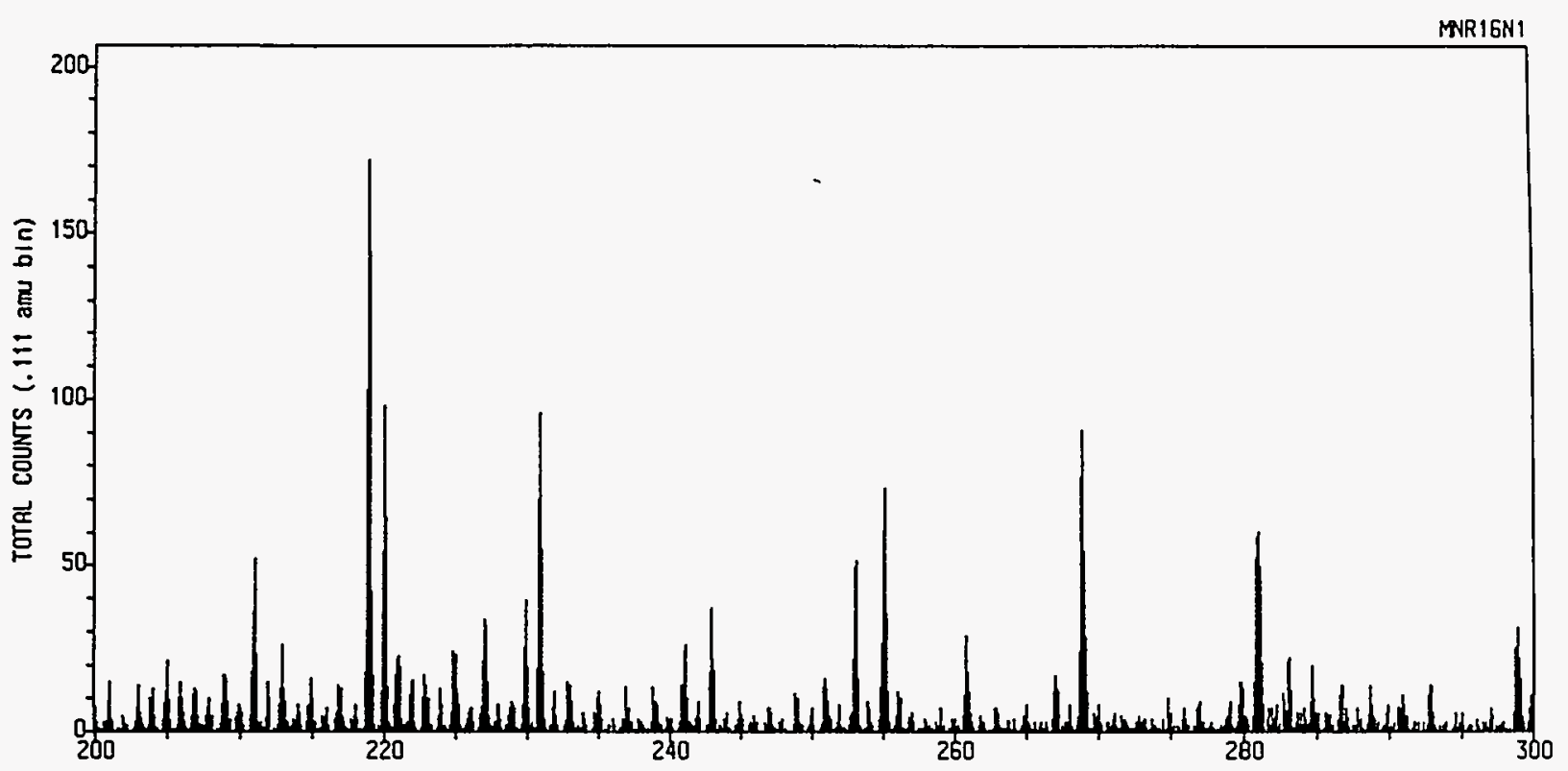

Fig. 5e. TOF mass spectrum, negative ions $\mathrm{m} / \mathrm{z}$ 200-300, MNR board.

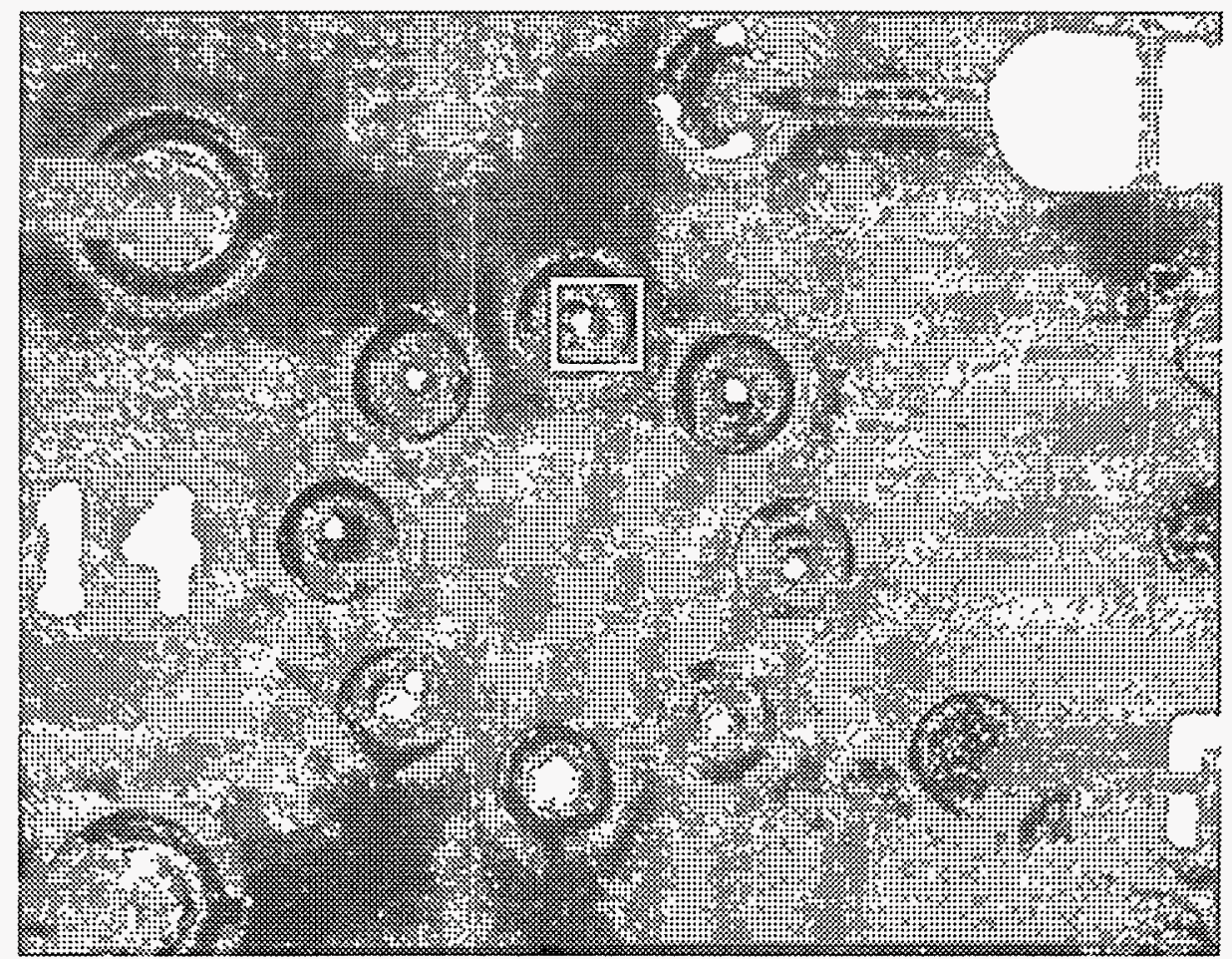

Fig. 6. Solder pad region from which data in Figs. 2-5 were taken. 
Table III

Negative Ion Mass Assignments (specific to MNR board)

$\begin{array}{rrrl}\text { Intensity } & \text { Mass } & \text { Norm.Int. } & \text { Formula } \\ \text { [Counts] } & \text { [amuI } & & \\ 69591 & 11.9979 & 0.3918 & \text { C } \\ 177605 & 13.0075 & 1.0000 & \text { CH } \\ 20256 & 14.0204 & 0.1141 & \text { CH2 } \\ 1405 & 15.0116 & 0.0079 & \text { HN } \\ 437860 & 15.9897 & 2.4654 & \text { O } \\ 240240 & 17.0009 & 1.3527 & \text { HO } \\ 900 & 17.9944 & 0.0051 & \text { H2O } \\ 731825 & 18.9996 & 4.1205 & \text { F } \\ 16831 & 24.0015 & 0.0948 & \text { C2 } \\ 34359 & 25.0135 & 0.1935 & \text { C2H } \\ 6425 & 26.0131 & 0.0362 & \text { C2H2 } \\ 3231 & 30.9992 & 0.0182 & \text { CF } \\ 4613 & 31.9707 & 0.0260 & \text { O2 } \\ 1267 & 32.9732 & 0.0071 & \text { HO2 } \\ 4786 & 34.9639 & 0.0269 & \text { Cl } \\ 1263 & 36.0006 & 0.0071 & \text { C3 } \\ 2256 & 36.9833 & 0.0127 & \text { 37CL } \\ 4558 & 37.9951 & 0.0257 & \text { F2 } \\ 1267 & 39.0245 & 0.0071 & \text { C3H3 } \\ 952 & 40.0029 & 0.0054 & \text { CH2 } \\ 2431 & 41.0137 & 0.0137 & \text { CHN2 } \\ 920 & 42.0127 & 0.0052 & \text { C2H2O } \\ 3315 & 43.0092 & 0.0187 & \text { CHNO } \\ 1162 & 45.0100 & 0.0065 & \text { HN2O } \\ 1432 & 47.9732 & 0.0081 & \text { SO } \\ 1344 & 49.0113 & 0.0076 & \text { C4H } \\ 748 & 50.9685 & 0.0042 & \text { O2F } \\ 664 & 58.0145 & 0.0037 & \text { CH2N2O } \\ 529 & 59.0248 & 0.0030 & \text { CH3N2O } \\ 951 & 59.9625 & 0.0054 & \text { CO3 } \\ 769 & 61.9931 & 0.0043 & \text { NO3 } \\ 2808 & 63.9705 & 0.0158 & \text { SO2 } \\ 940 & 64.9997 & 0.0053 & \text { C4HO } \\ 579 & 66.9963 & 0.0033 & \text { H3O4 } \\ 3182 & 68.9946 & 0.0179 & \text { C3HO2 } \\ 540 & 71.0271 & 0.0030 & \text { C2H3N2O } \\ 652 & 73.0061 & 0.0037 & \text { C6H } \\ 726 & 77.9833 & 0.0041 & \text { NO4 } \\ 8268 & 78.8854 & 0.0466 & \text { Br } \\ 2394 & 79.9692 & 0.0135 & \text { SO3 } \\ 8803 & 80.8837 & 0.0496 & 81 B r \\ 2235 & 82.9698 & 0.0126 & \text { O4F } \\ 565 & 85.0201 & 0.0032 & \text { C3H3NO2 } \\ 723 & 92.9945 & 0.0041 & \text { HN2O4 } \\ 624 & 96.9828 & 0.0035 & \text { HO6 } \\ 1100 & 118.9897 & 0.0062 & \text { C2HNO5 } \\ 1251 & 168.9685 & 0.0070 & \text { CHN2O8 } \\ 519 & 398.7514 & 0.0029 & \\ 135 & 418.7762 & 0.0008 & \text { O25F } \\ 3852 & 498.6580 & 0.0217 & \\ 329 & 525.6917 & 0.0019 & \\ & & & \end{array}$




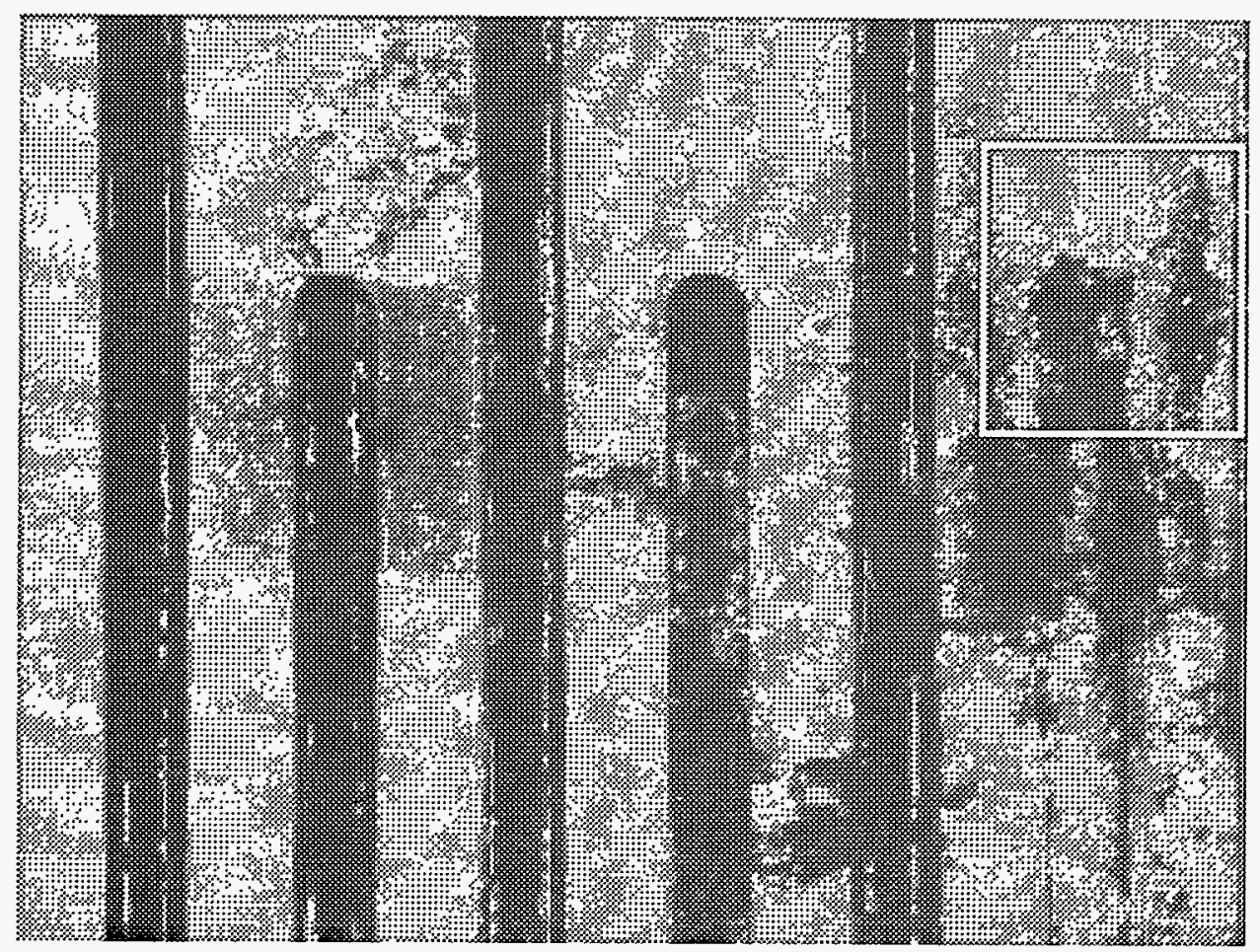

Fig. 7a. Photomicrograph of SIR board at $\sim 10 x$ magnification. 


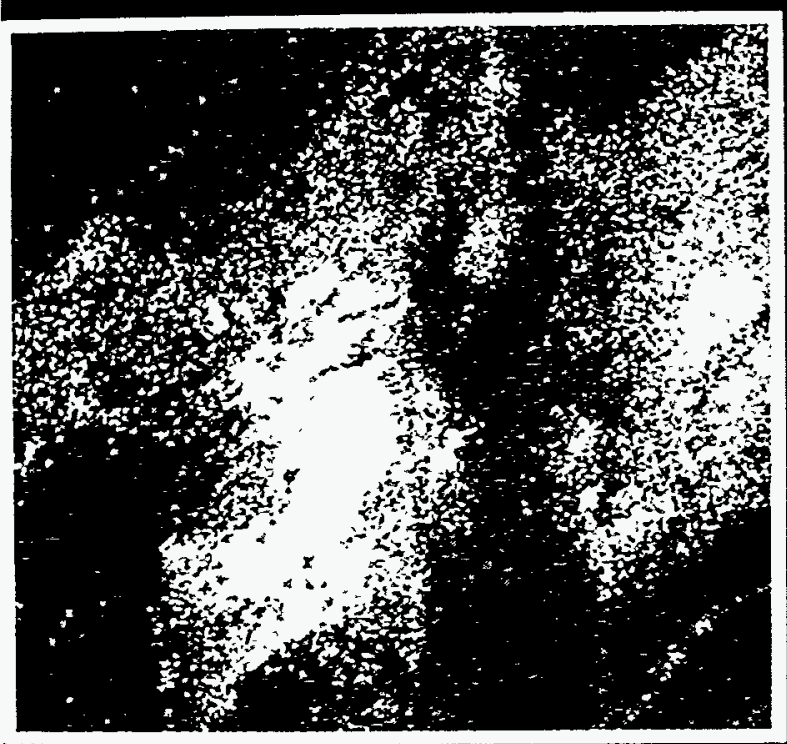

a

5200 $\mathrm{mm}$

equal

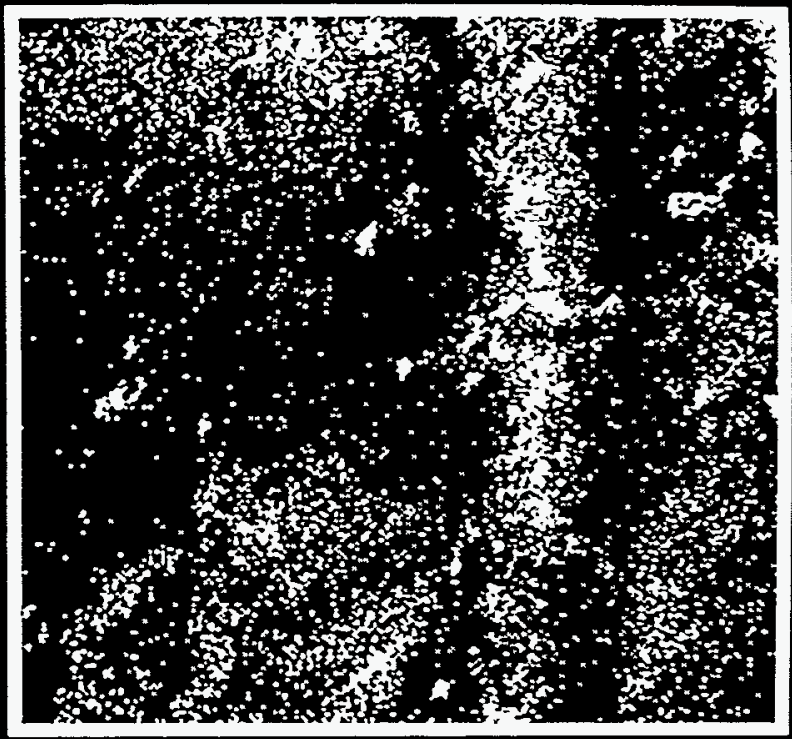

AL

$5020 \mathrm{~mm}$

equal

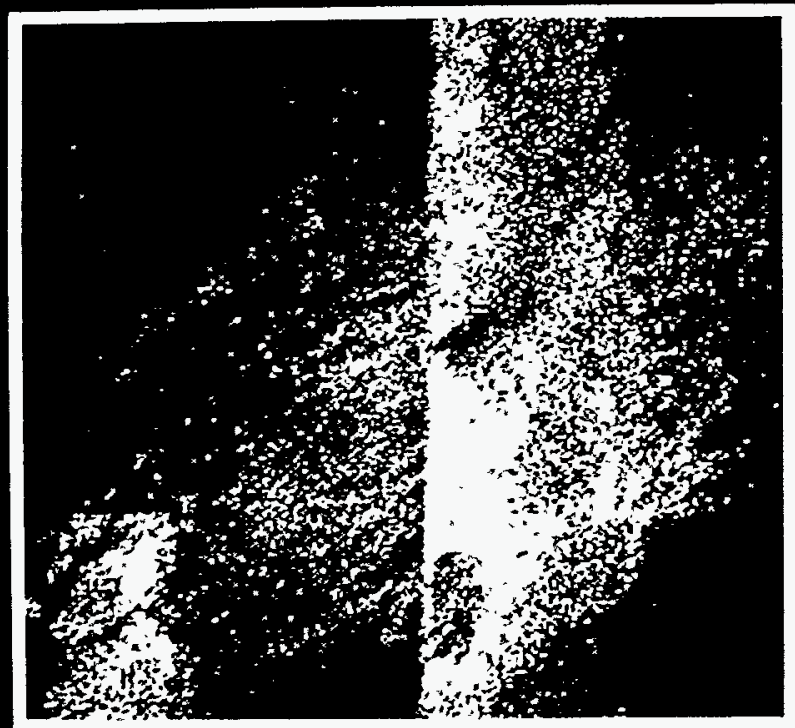

PB

$5000 \mathrm{~m}$

equal

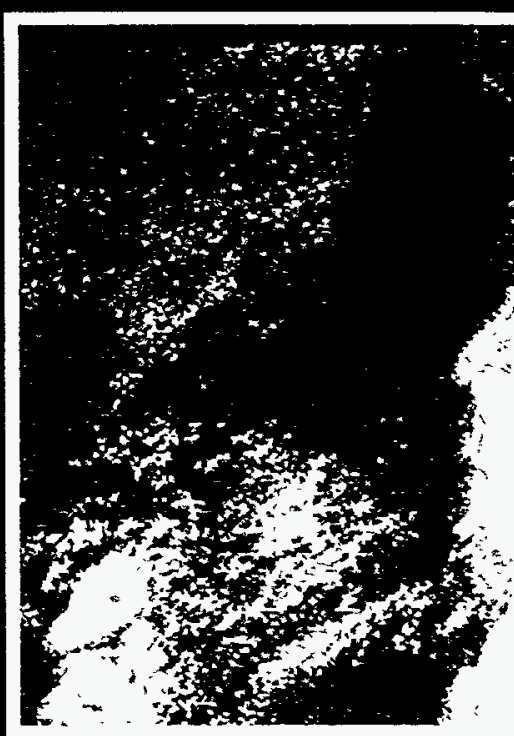

52an m

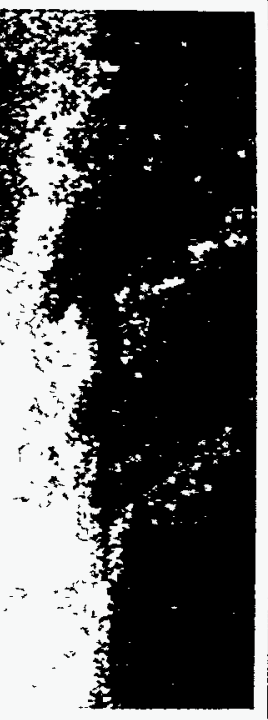

equal

Fig. 7b. SIMS positive ion maps of highlighted region in Fig. 7a. 

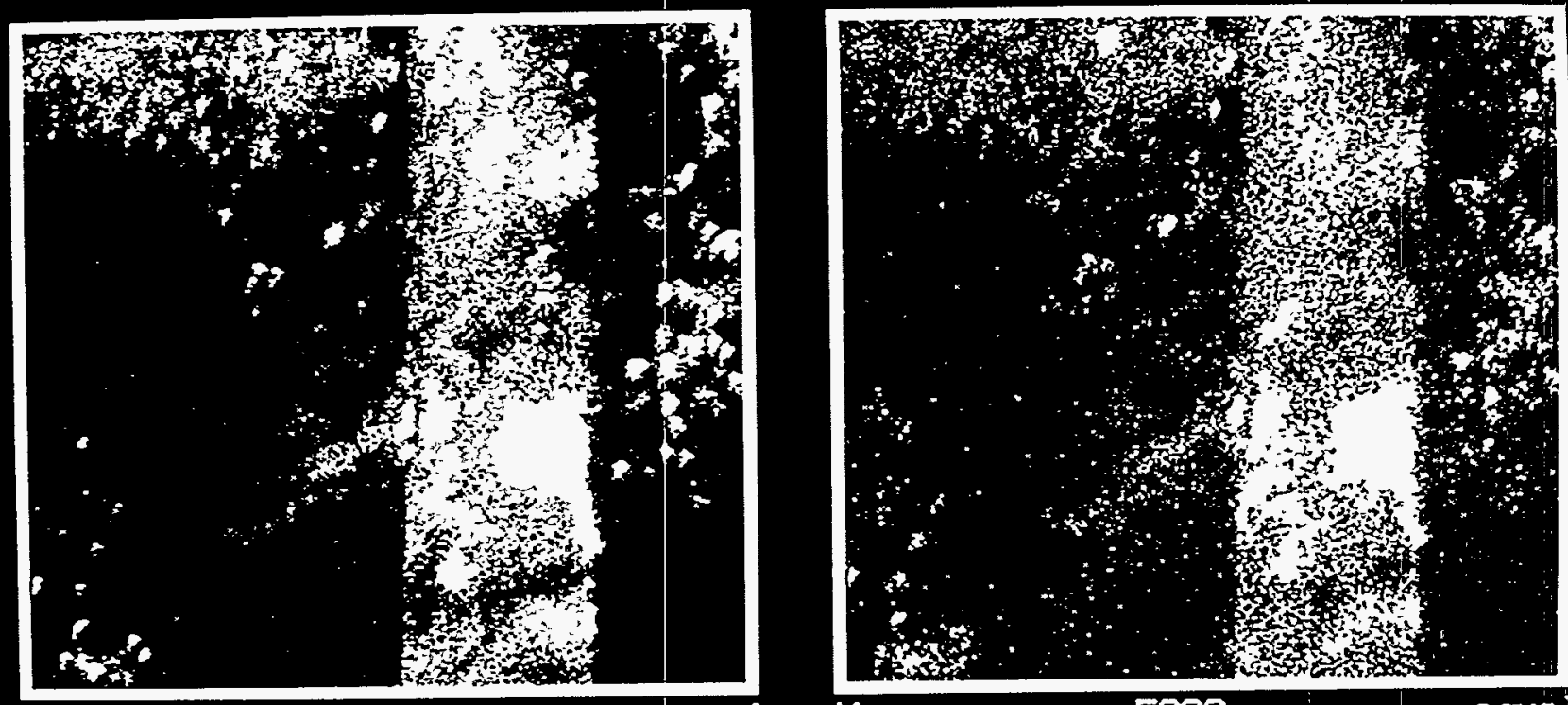

Na

$5000 \times m$

equal

K

Sga日um

equal
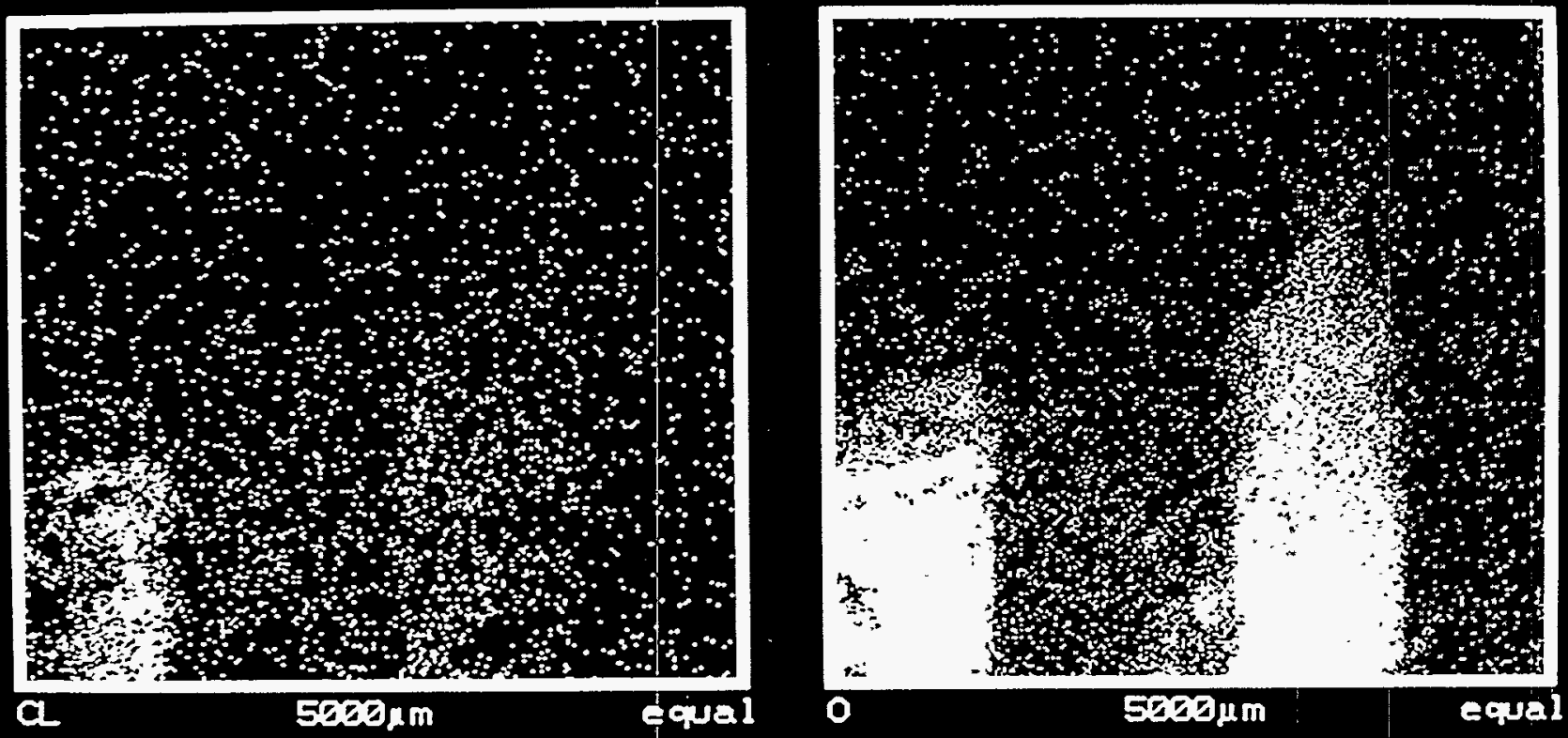

Fig. 7c. SIMS ion maps $\left(\mathrm{Na}^{+}, \mathrm{K}^{+}, \mathrm{Cl}^{-}, \mathrm{O}^{-}\right)$of highlighted region in Fig. 7 a. 

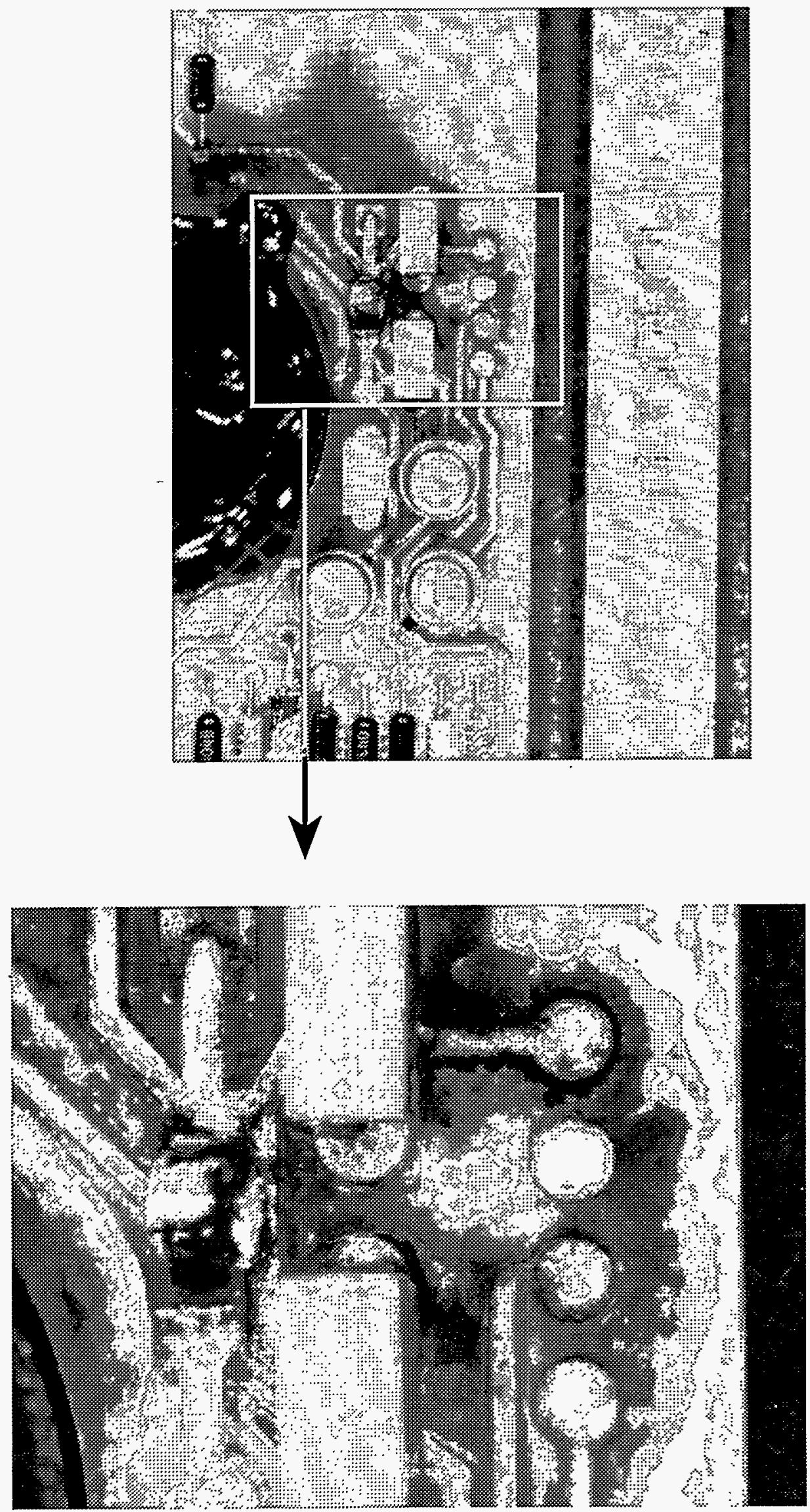

Fig. 8. Photomicrograph of functional board. Highlighted region displays extreme corrosion of diode. 
chemical residues in the immediate vicinity of the board. These deposits were characterized by EMPA, AES, and SIMS mapping (Figs. 9 and 10) and were found to consist of aluminosilicates with high levels of molybdenum oxide. The molybdenum oxide residue is unusual in that it has not been observed in previously analyzed PWBs retrieved from environmental test chambers. The source of this unusual contaminant was traced to the interior of the suspect diode. A microsection of the questionable diode type was analyzed using EMPA and SIMS from a board that under optical examination displayed initial corrosion attack. The corrosion pathway was traced to water and humidity penetration at the point where the solder cap, the covering ceramic, and the diode interior material (molybdenum metal) meet (Figs. 11 and 12). The ceramic coating appeared slightly porous and could, in principle, retain adipic and formic acid residues resulting from the self-cleaned solder process. In practice, only the diodes that clearly displayed water dripping on them had the prominent corrosion attacks. This diode type clearly was not meant to see this type of service. For conformal coated boards (boards coated with a water-resistant polyurethane coating) the corrosion displayed by this type of diode was not evident.

\section{SUMMARY}

The following conclusions are drawn about the use of adipic and formic acids as solder flux components in the self-cleaned solder process process:

1. Conventional military specification and IPC testing procedures show no difference between traditional rosin/flux soldering and the self-cleaned solder process. They do not possess sufficient sensitivity for extremely low contamination levels of adipic and formic acid residues.

2. Nondestructive spectroscopic examination coupled with small-area photomicroscopy can clearly identify solid deposits related to decomposition products of the adipic and formic acid components used in the self-cleaning process.

3. Scanning Auger electron microscopy, FTIR microscopy and TOFMS examination clearly identified these additional deposits as deriving from carboxylic acid decomposition byproducts that were not readily soluble in CFC rinse solutions traditionally used in ASTM surface hydrocarbon/grease analysis.

4. Very good long term stability and reliability are indicated in the temperature and temperature and humidity testing despite the appearance of solid deposits arising from the decomposition of the adipic and formic acid components inherent in this solder process. See the complete project test result documentation for the specific details regarding this portion of the project. With the exception of one specific porous diode type, no serious solder corrosion problems were identified over the span of experiments and simulated aging encompassed by this project.

\section{SUGGESTIONS AND FUTURE WORK}

Despite the encouraging results obtained from the project, several analytical needs that might further enhance the implementation of the technology. Specifically, the need for an easy, rapid, quantitative, nondestructive analytical measure of adipic and formic residue is certainly warranted. Such a technique could, in principle, be developed based upon modification of current HPLC quantification techniques. Such modification would require further experimentation involving optimizing wash and elution solvents. Such testing would strongly complement ionographic testing (testing for ionic contaminants) but would be more specific for residue components of the self-cleaning process. Furthermore, with the push toward less costly and technologically superior alternative solder flux components that might degrade at lower thermal temperatures such a technique would help identify specific components in the solder flux. As an aid in identifying exact temperature regimes and 


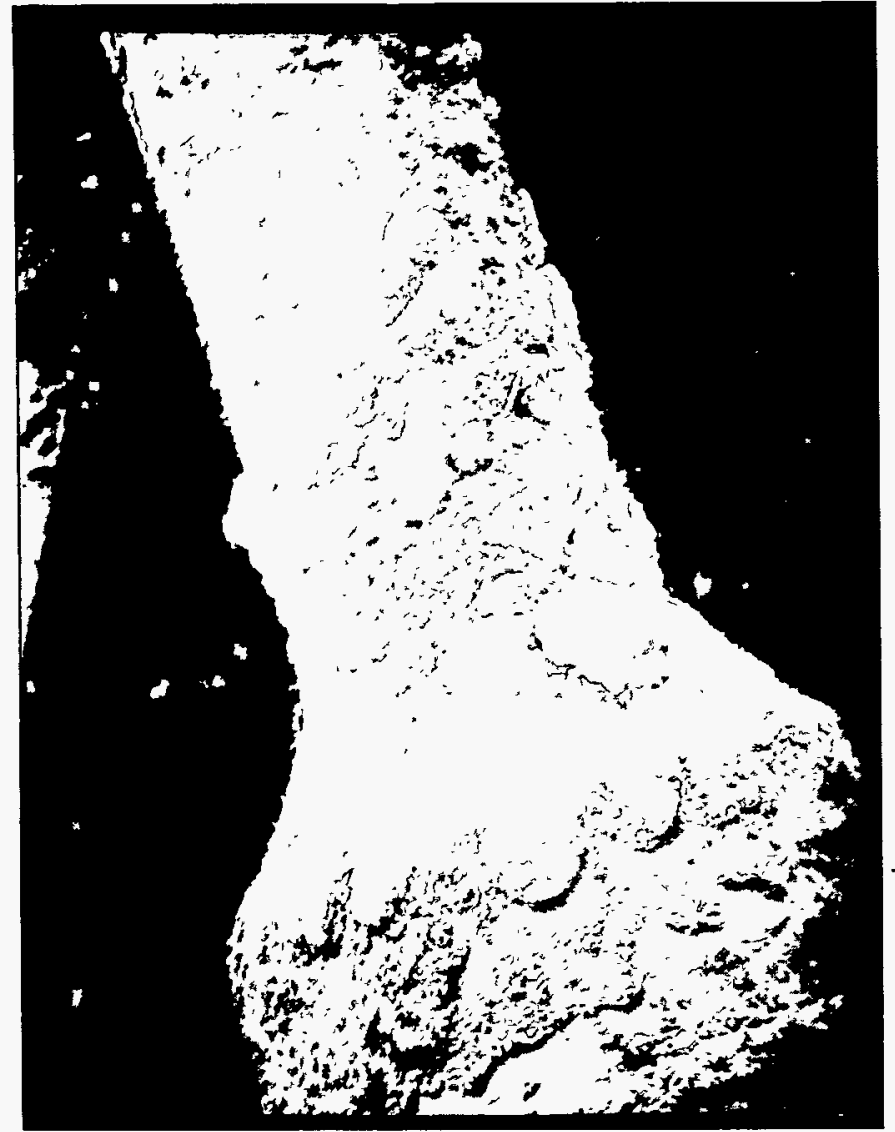

a.

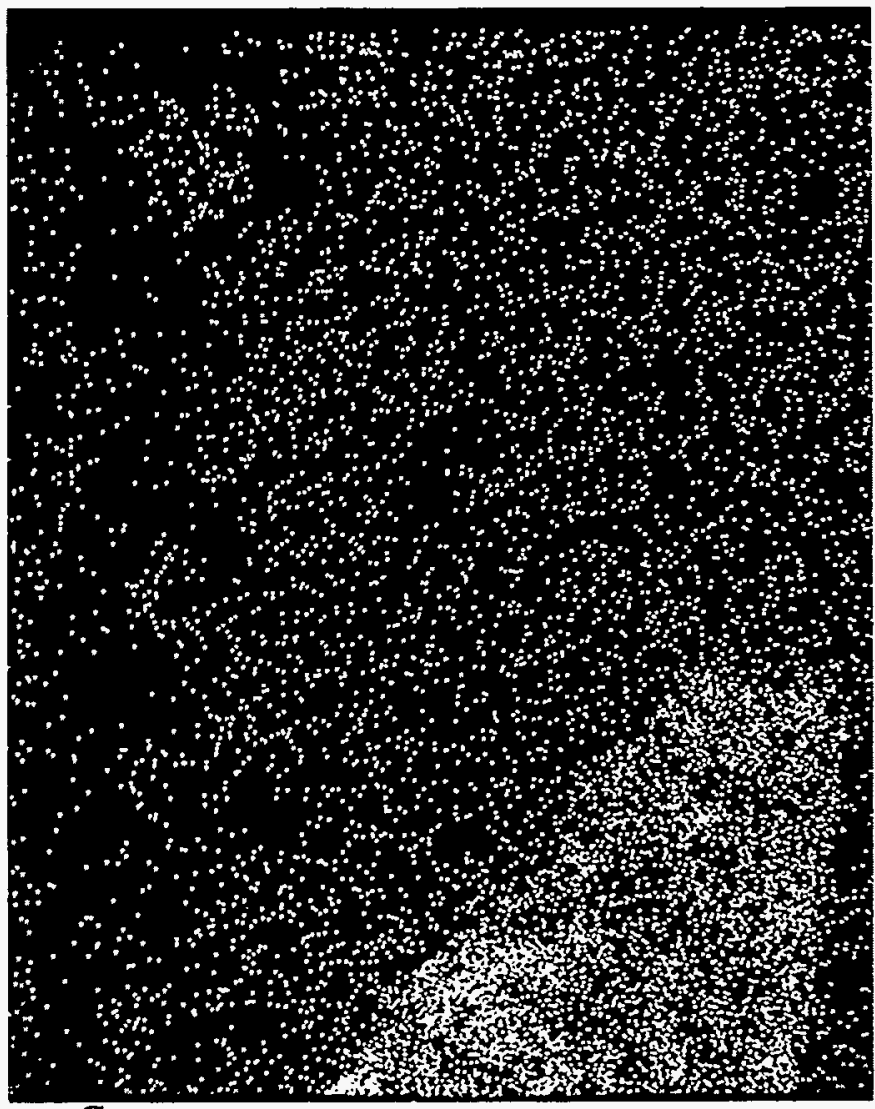

c. $-\mathrm{Cu}$

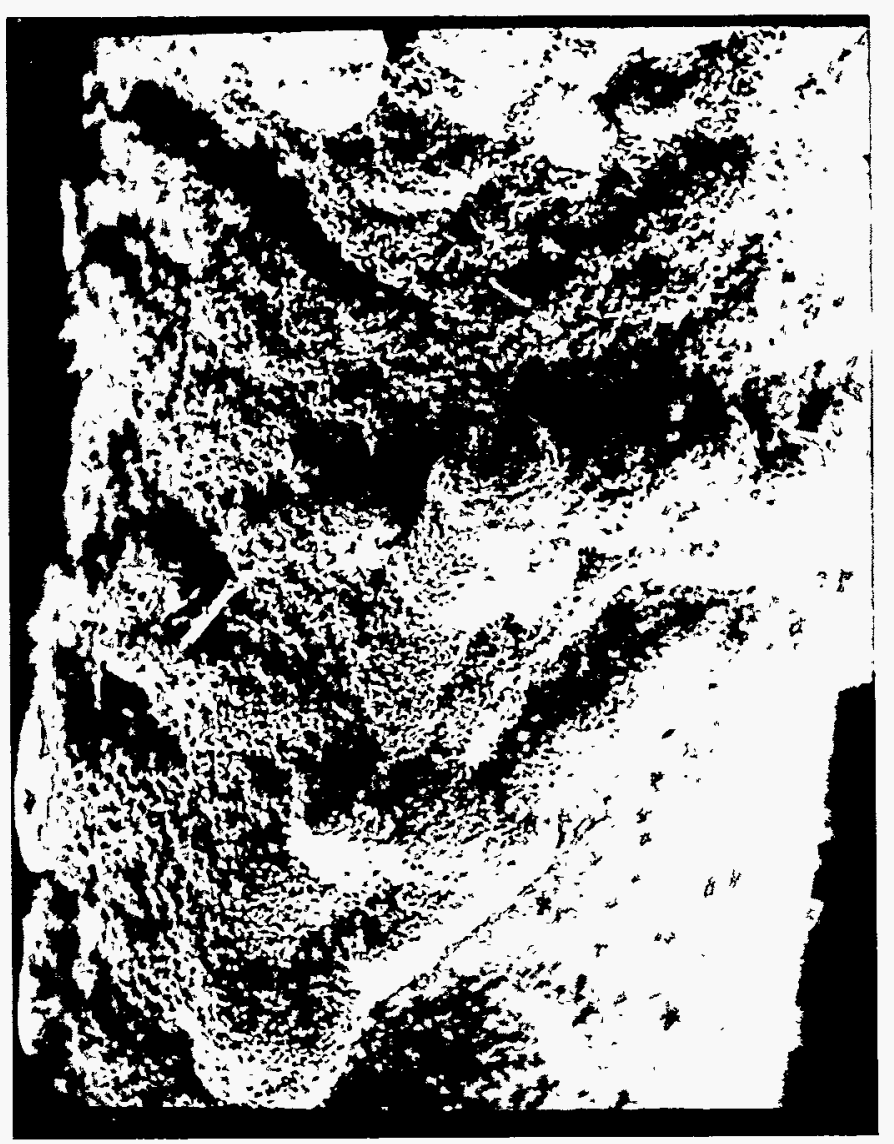

b.

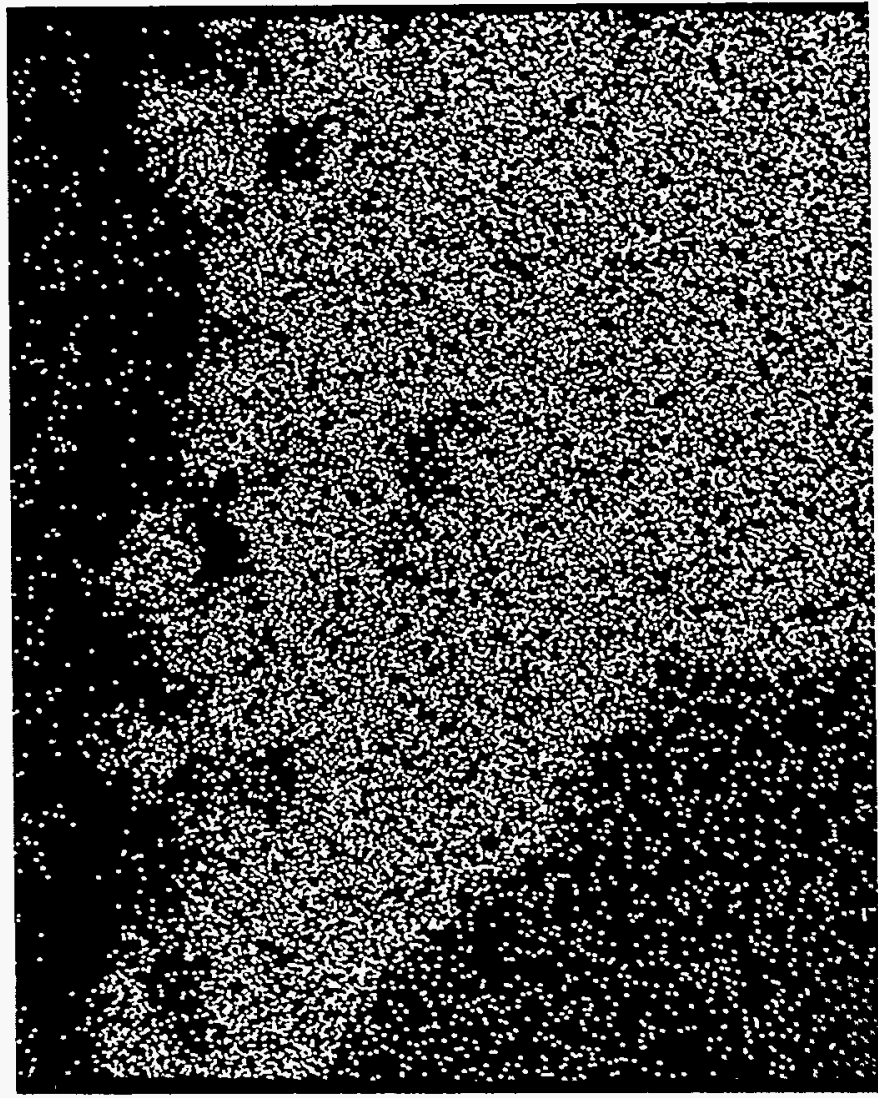

d. $-\mathrm{Zn}$.

Fig. 9a. SEMs of faulty diode showing corrosion deposit (a, 40x magnification; $\mathrm{b}, 100 \mathrm{x}$ magnification). Elemental $x$-ray maps corresponding to photomicrograph $b$. 


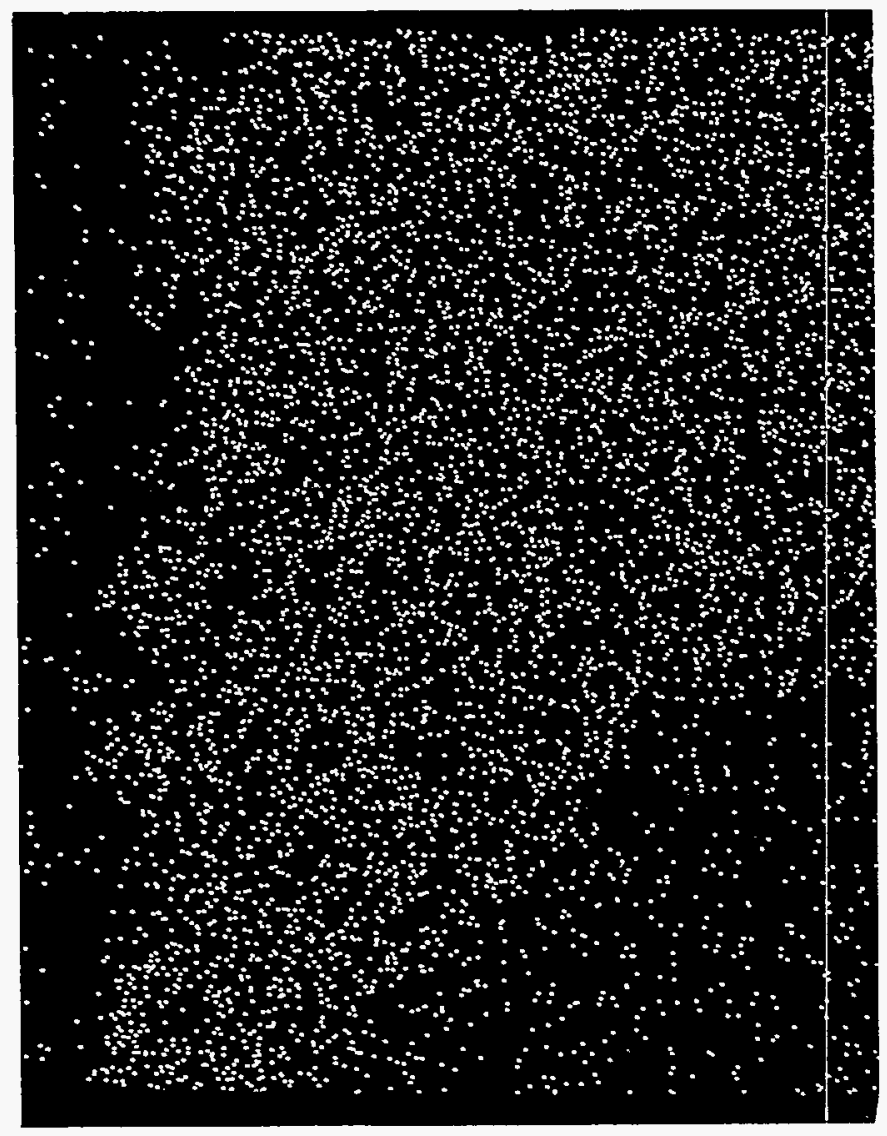

a. - Mo

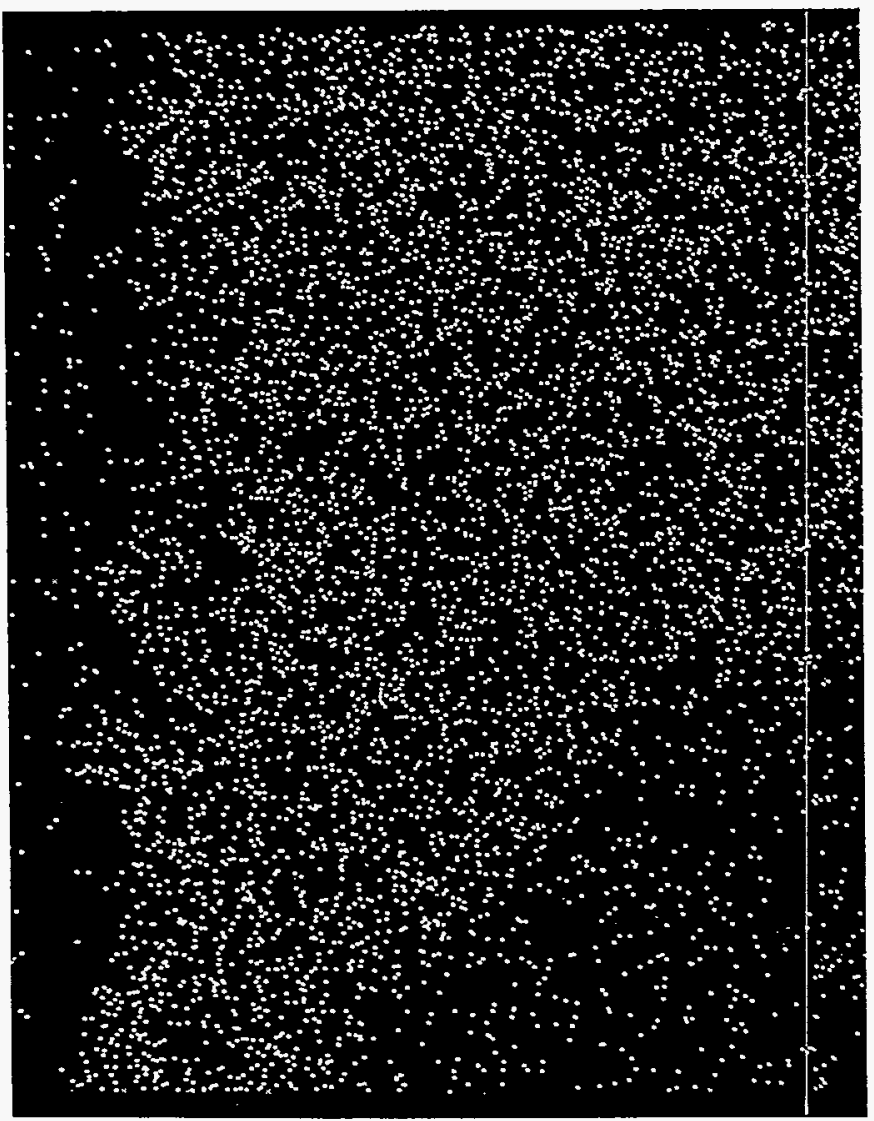

c. $-\mathrm{O}$

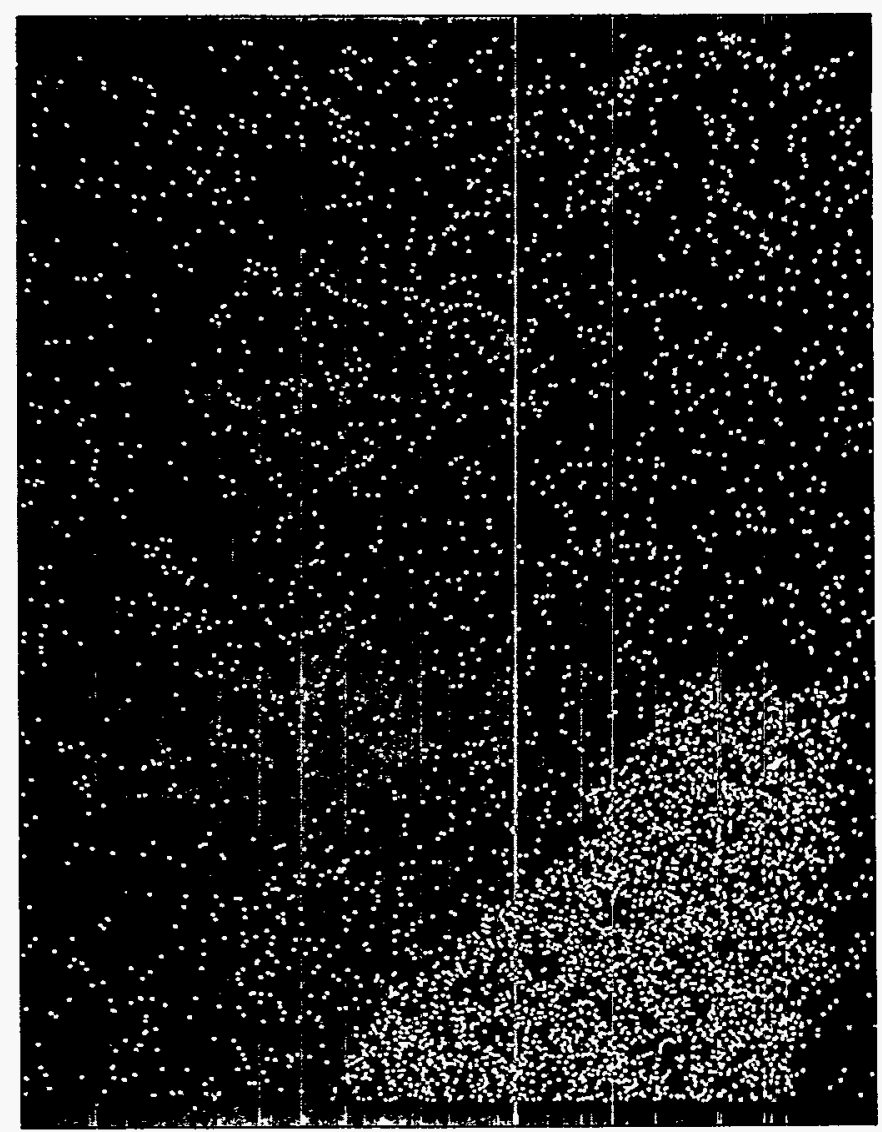

b. $-\mathrm{Pb}$

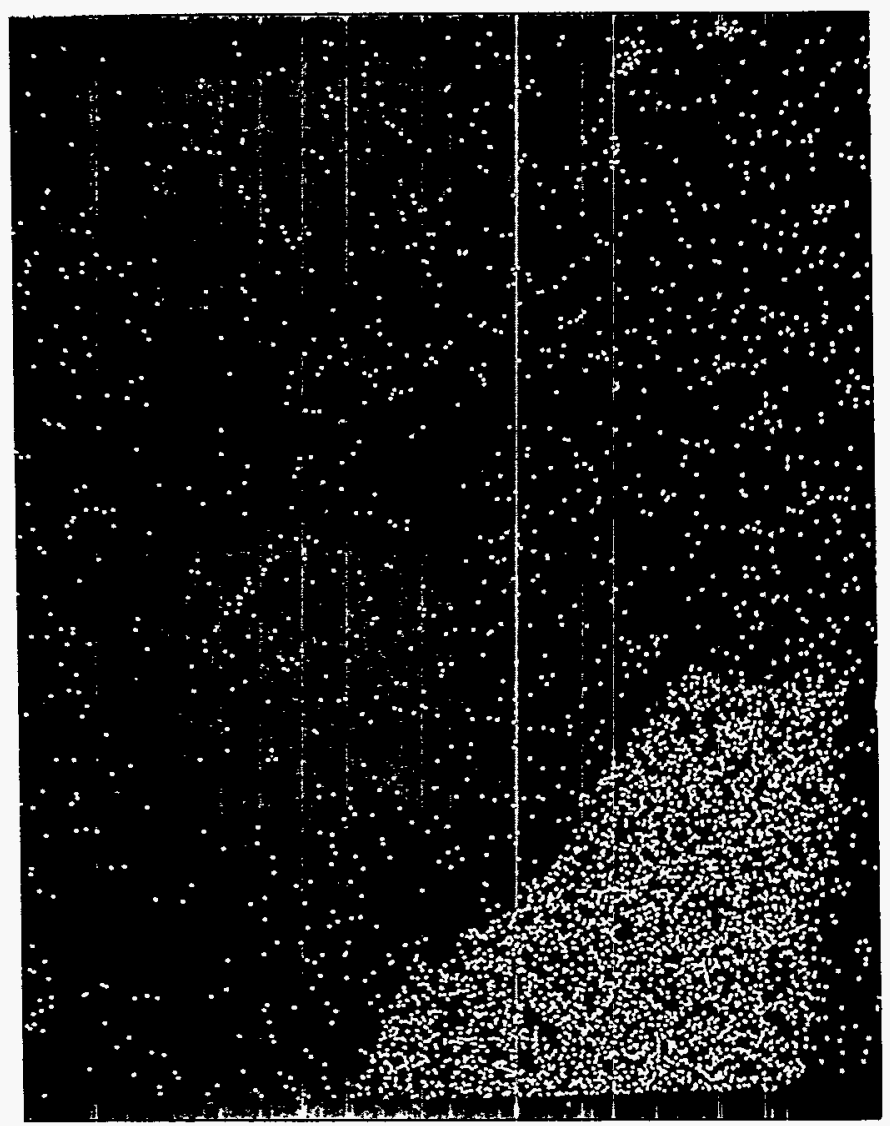

d. - Sn

Fig. 9b. Elemental x-ray maps corresponding to photomicrograph of Fig. 9a(b). 

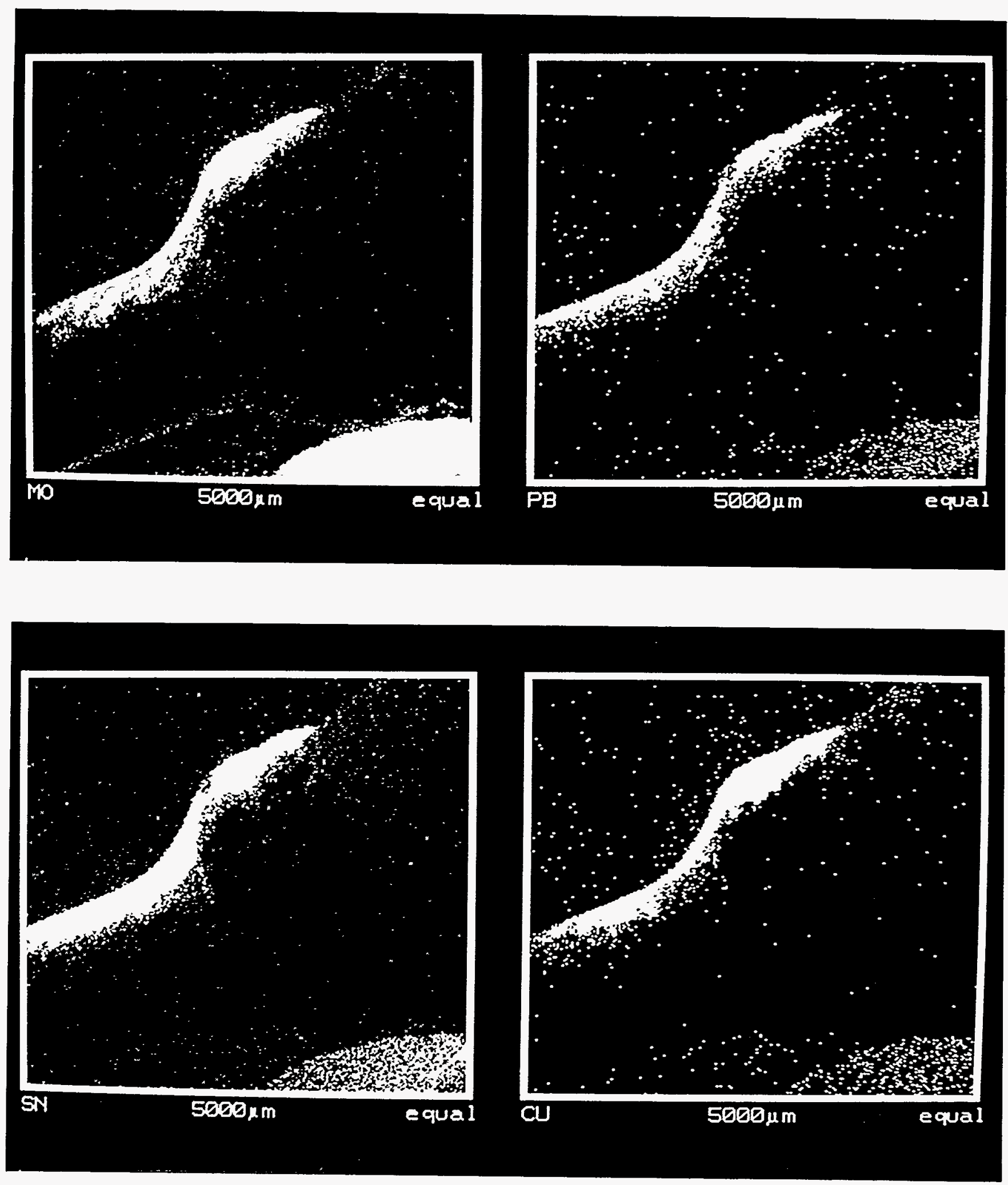

Fig. 10. SIMs elemental maps showing edge of affected diode type. Shadowing of diode by physical positions of ion gun and mass analyzer is very apparent over portions of figure. 

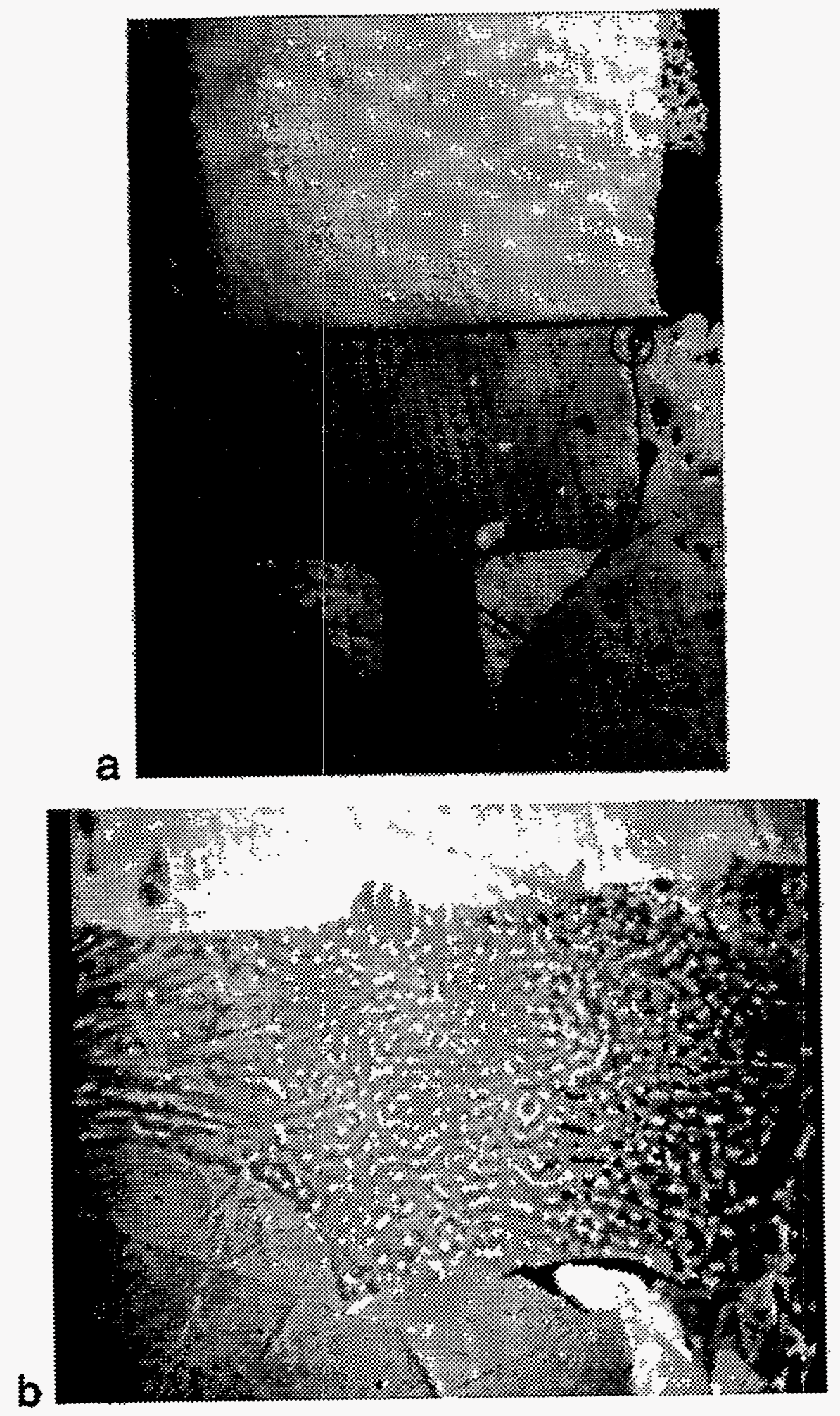

Fig. 11. (a) Optical micrograph of diode that is metallographically mounted on PWB, (b) secondary electron image at $1500 \mathrm{x}$ of circles region of (a) (light area is $\mathrm{P}$ rich $\mathrm{Cu}$ region, note depletion in outer edge). 

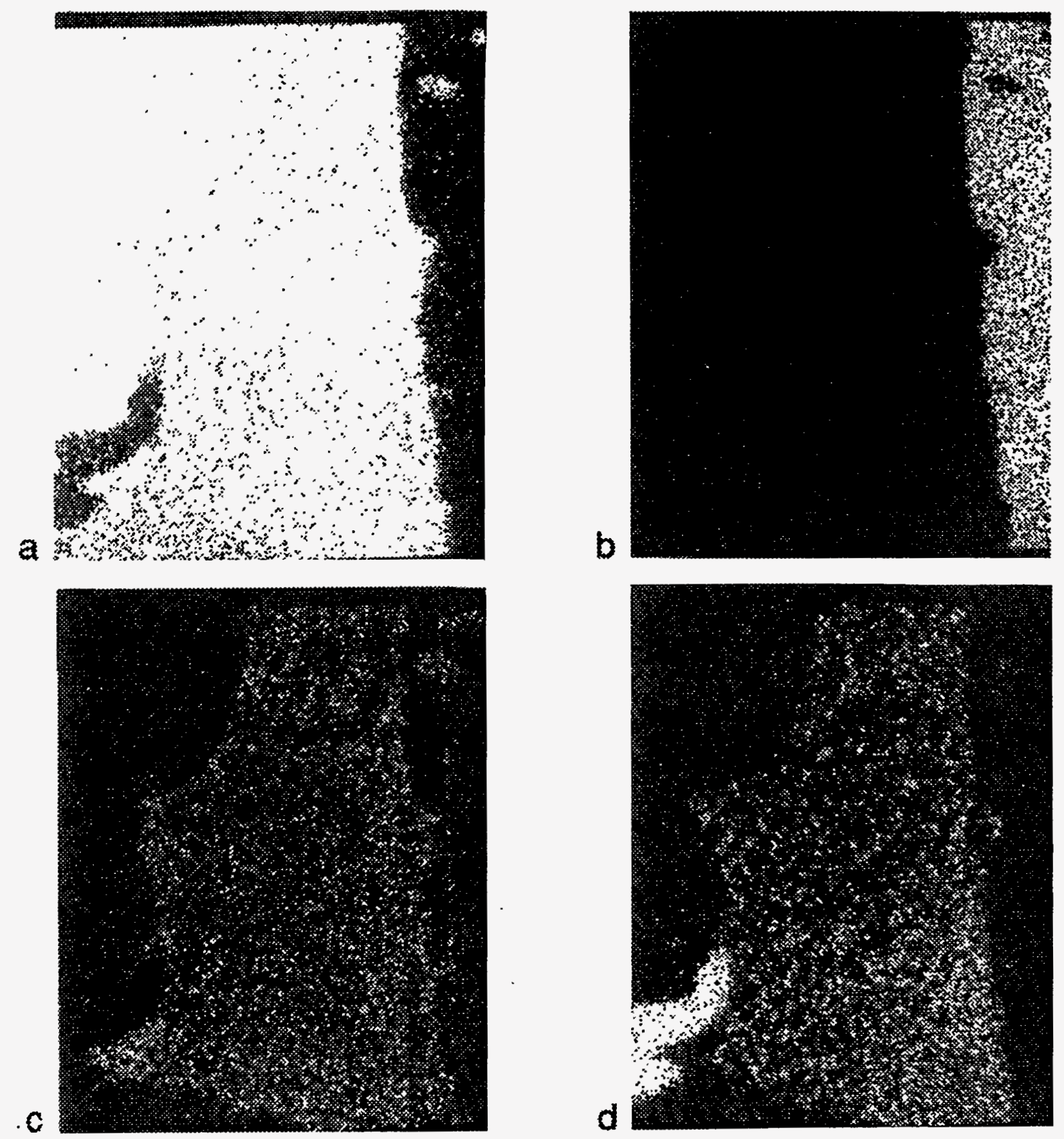

Fig. 12. Composite EMPA x-ray maps of the SEM in Figure 4.3b: (a) $\mathrm{Cu}$, (b) Mo, (c) $\mathrm{P}$, and (d) Ag. 
surface chemistry pertinent to the solder flux degradation mechanism(s), physical chemistry experiments on the detailed interactions of adipic and formic acid at tin and lead oxide surfaces are envisioned as part of our fundamental surface science research efforts.

\section{REFERENCES}

1. R. Iman, D. Anderson, M. Armendariz, L. Lichtenberg, P. Van Buren, M.T. Paffett, "Evaluation of Soldering Process Designed to Eliminate the Use of Ozone Depleting Chemicals," IWRP CRADA Report No. CR91-1026, Issued by Sandia National Laboratories, Albuquerque, NM , 11/1992.

2. J. Shandle, "Cutting Out Cleaning," Electronics, 1/1991, pg. 41.

3. M.A. Nasta, P.O. Runco, G.R. Hill, and J.C. Kutt, "The Effect of Organic Diacids on Solderability," Mellon Institute 2nd International Conference on Flux Technology, 9/5 7/1990, Tab 5, TP-894.

4. D.A. Elliot and L.J. Tubini, "Characterizing Residues from Controlled Atmosphere Wavesoldering," Mellon Institute 2nd International Conference on Flux Technology, 9/5 7/1990, Tab 7, TP-901.

5. C. Rayleigh, "Attributes of Formic Acid in Soldering," Motorola Internal Memorandum, MEMO 90-031-MRPCR, 8/28/90, Motorola Corporate Research Center, Schaumberg, IL. 